University of Washington Tacoma

UW Tacoma Digital Commons

SIAS Faculty Publications

School of Interdisciplinary Arts and Sciences

2017

\title{
Modulators of IgG Penetration Through the Blood- Brain Barrier: Implications for Alzheimer's Disease Immunotherapy
}

John M. Finke

University of Washington Tacoma, jfinke@uw.edu

William A. Banks

Follow this and additional works at: https://digitalcommons.tacoma.uw.edu/ias_pub

\section{Recommended Citation}

Finke, John M. and Banks, William A., "Modulators of IgG Penetration Through the Blood-Brain Barrier: Implications for Alzheimer's Disease Immunotherapy" (2017). SIAS Faculty Publications. 825.

https://digitalcommons.tacoma.uw.edu/ias_pub/825

This Article is brought to you for free and open access by the School of Interdisciplinary Arts and Sciences at UW Tacoma Digital Commons. It has been accepted for inclusion in SIAS Faculty Publications by an authorized administrator of UW Tacoma Digital Commons. 
Title:

Modulators of IgG penetration through the blood-brain barrier: Implications for Alzheimer's Disease immunotherapy.

Authors:

John M. Finke ${ }^{1}$ and William A. Banks ${ }^{2,3}$

Affiliations:

${ }^{1}$ Division of Sciences and Mathematics, Interdisciplinary Arts and Sciences, University of Washington Tacoma, Tacoma, WA, USA

${ }^{2}$ Geriatric Research Education and Clinical Center, VA Puget Sound Health Care System, Seattle, WA, USA

${ }^{3}$ Division of Gerontology and Geriatric Medicine, Department of Geriatric Medicine, University of Washington School of Medicine, Seattle, WA, USA

Introduction:

Antibody drugs represent a viable treatment option for cancer and autoimmune conditions $[43,65,74,95,109,146]$. However, the future of antibody therapeutics in the treatment of central nervous system (CNS) disorders remains unclear. This uncertainty is underscored by a growing list of antibody drug trials that failed to meet clinical endpoints in the treatment of Alzheimer's disease (AD) and multiple sclerosis (MS) $[43,51,54,86,102,126]$. By contrast, many peripheral nervous system (PNS) conditions have proved tractable to antibody treatments $[43,146]$. One major difference between the CNS and PNS is that the tissues of the CNS are both physically sequestered and actively protected from chemical and biological entities in the blood via the blood-brain barrier (BBB) $[20,22]$. The primary limiting components of the BBB are a layer of endothelial cells (ECs) connected via cross-linked "tightjunctions" that severely restrict extracellular diffusion of large molecules into the brain parenchyma, greatly decreased micropinocytosis, and a loss of transcellular leakage $[20,22]$. Thus, the failure of antibody treatments for CNS diseases may simply stem from the inability of these drugs to reach their intended targets [22]. This problem poses a significant challenge for large protein drugs, such as antibodies, for which there is no specific mechanism in the BBB for entering the brain [16]. However, if approaches can be developed that can deliver antibody drugs across the BBB, many therapeutics that failed in previous clinical trials may get a second chance.

Here, we review antibody therapy research of AD from the perspective of BBB permeability. Although presently unsuccessful from a clinical standpoint, previous AD clinical trials with antibodies have established the importance of improving antibody penetration into the brain $[43,51,54,86,102,126]$. BBB drug penetration is also a critical facet in the treatment of other CNS disorders as well [43]. Development of AD antibody drugs with increased penetration into the brain parenchyma will enable clinicians to transfer this success into new classes of antibody therapy for Parkinson's disease, MS, and brain cancer.

In the case of AD treatment, early antibody drug design initially focused on the drug's ability to selectively target a particular protein $[11,51,54,86,90,102,126]$. The most common targets were those that were thought to modify the levels of toxic oligomers and aggregates of the $A \beta$ peptide in the brain 
$[11,51,54,86,90,102,126]$. During the development of these antibody therapeutics, studies had shown IgG antibodies delivered to the brain to induce different and more profound effects than those delivered intravenously $[94,140,144]$. However, redesigning antibody drugs in the pipeline for increased BBB penetration was a secondary priority $[90,102]$.

The initial emphasis on prioritizing antibody:target binding over BBB pharmacokinetics stemmed from a number of factors. First, some studies supported the premise that the BBB becomes "leaky" or more permissive to passage as $A D$ progresses $[48,56,78,93,164]$. Second, while most studies indicate low BBB penetration of IgG in normal humans and mice as well as those with AD (0.1-0.2\% brain:blood concentrations) $[12,16,23,47,51,97]$, some research suggested that the BBB penetration by anti-A $\beta \lg G$ might be higher $[34,49]$. Third, early preclinical studies and Phase I trials also suggested that therapeutic IgG could alter AD pathology at relatively low brain levels in the brain via mechanisms of peripheral sink [47], central sink [23,129], central sequestration [156], and/or neutralization of $A \beta$ toxicity $[52,97,121]$. In particular, the peripheral sink mechanism was supported by early studies reporting lower serum levels of anti-A $\beta$ IgG in AD patients than healthy controls [55], although subsequent studies found contradictory reports of this particular biomarker [83].

Given the benefit of hindsight, we now know that AD-related BBB disruption does not increase penetration of therapeutic IgG significantly. Scientific evidence suggesting an excessively leaky BBB in $A D$ patients was predicated on an increased level of peripheral proteins in cerebrospinal fluid (CSF) and in immunostained neural tissue [58]. Despite this evidence, an equivalent number of studies found no difference in this metric between $A D$ patients and age-matched controls $[57,58]$. One complication in these studies is that most $A D$ patients also experience vascular disease, which is much more highly correlated with BBB disruption than AD $[57,58]$. In addition, lower CSF production and A B BBB transporter activity are found in $A D$, both which could also increase peripheral protein concentrations in the CSF $[20,21,57,72,135]$. Lastly, all studies that explicitly tracked BBB penetration of Positron Emission Tomography and Magnetic Resonance Imaging sensitive dyes in human subjects [57] and IgG influx into mice $[16,19,23]$ did not find a correlation between drug penetration and AD. In fact, drug penetration has been shown to remain low even when the BBB is known to be physically disrupted [35]. In light of these findings, it is reasonable to conclude that typical anti-A $\beta$ IgG drugs access the brain parenchyma at low levels in $A D$ patients.

A more urgent interest in antibody BBB penetration emerged after the first generation of antibody therapeutics for $A D$ failed to deliver the desired results in Phase III clinical trials $[51,54,86,97,126]$. A $\beta$ oligomers and aggregates in the CNS were not reduced to the degree found in animal models, either being lower [126] or remaining unchanged [51,54] after treatment. Most importantly, there was a notable lack of significant clinical efficacy compared to placebo for all treatments $[51,54,86,97,126]$. The treatments did shift $A \beta$ and/or tau biomarkers in the desired direction $[54,126]$ and select patient subgroups showed a possible benefit $[54,86]$. However, these effects were small and none of these treatments are viable in their current formulation for treatment of $A D$ patients. Target selection by anti- $A \beta$ antibodies is likely to remain an important factor. But many new efforts have focused on methods or modifications that will increase the concentration of these antibodies in the brain $[27,128]$. If such methods are successful, future anti-A $\beta$ antibody therapeutics may prove more effective than those tested up to this point. 
Recent results of the PRIME study with the chimeric antibody aducanumab support the need to increase BBB penetration of antibodies and also provides encouraging results for a viable treatment of $A D$ [134]. This Phase I study indicated that aducanumab was capable of both reducing amyloid plaque load and slowing cognitive decline in humans. Aducanumab differs from other monoclonal therapeutic antibodies in that it is a human antibody that was designed to be highly selective for aggregated forms of $A \beta$ [134]. Specifically, the affinity of aducanumab for aggregated $A \beta$ is more than 1000 -fold higher than that of monomeric $A \beta\left(K_{D}>10 \mu M\right)$ [134]. In addition to this enhanced target specificity and affinity, two other notable outcomes beyond the clinical metrics were also noted after the clinical trial. The first outcome is that the BBB penetration was 13 times higher (1.3\% brain to plasma) than typical therapeutic antibodies ( $0.1 \%)[97,134]$. The second outcome is that its mode of action for $A \beta$ reduction appears to rely on microglial activation within the brain itself than on facilitating export of $A \beta$ out of the brain [134].

The efficacy of advucanumab needs to be confirmed in a larger trial. That said, in comparison with previous studies, this trial establishes a positive correlation between BBB penetration and clinical efficacy of anti- $A \beta$ antibodies $[97,134]$. In addition, it also suggests a clinical model where a major clinical process, microglial activation, is effected by the antibody within the brain. If microglial activation is central to the success of this drug, increasing the concentration of aducanumab in the brain will be a key factor in its clinical outcomes. This review serves to explore the means to better achieve this goal.

\section{$\underline{\text { Increasing IgG influx }}$}

IgG influx into the brain is limited due to extensive tight junctions and other changes in the endothelial layer of the BBB [17]. Influx of endogenous antibodies does not occur by use of transporters or adsorptive transcytosis, but by the much slower extracellular pathways [17]. With only extracelluar pathways to use, the BBB influx rate of endogenous IgG is comparable to albumin $[16,113]$.

To increase anti-A $\beta \operatorname{IgG}$ delivery to the brain, a number of strategies are being developed to increase influx through the BBB (Figure 1). Influx-enhancement strategies roughly fall into one of three categories: (1) increasing influx through existing extracellular and transcytotic pathways; (2) a "Trojan Horse" approach in which the antibody, as a single engineered antibody or with a second engineered carrier molecule, is targeted to a specific BBB transport system and (3) targeted disruption of the BBB. The first two specifically increase the antibody influx while the third opens the BBB non-specifically.

Enhanced influx of IgG fragments. One approach that increased antibody influx was the use of $\mathrm{F}(\mathrm{ab})_{2}$ fragments of anti-A $\beta$ IgG. These fragments are able to penetrate the BBB at higher rates than their parent IgG constructs [115] with comparable therapeutic efficacy in AD animal models [143]. Even smaller scFv fragments of anti-A $\beta$ IgG (27 kDa) likewise result in increased BBB influx, $A \beta$ clearance, and cognitive improvement in $A D$ mouse models [101]. Smaller yet are anti-A $\beta V_{H} H$ single chain domains, i.e."nanobodies", derived from llama antibodies (12 kDa) [59]. In addition to their high thermal and chemical stability, $\mathrm{V}_{\mathrm{H}} \mathrm{H}$ domains exhibit a comparable antigen affinity to scFv domains despite having only three complementarity determining regions [97]. An anti-A $\beta V_{H} H$ fragment was reported to have an unprecented brain to blood ratio of 0.6 in $A D$ mouse models [124]. However, the ability of anti-A $\beta V_{H} H$ nanoboddies to clear CNS amyloid and improve AD pathology in AD mouse models remains to be seen 
[104]. Why these fragments cross more quickly is not completely clear, but they likely employ some mechanism in addition to the extracellular pathways, possibly adsorptive transcytosis.

Despite the advantages of antibody fragments, one notable limitation is their high turnover in serum $[59,101,124]$. This rapid loss of peripheral drug concentration prevents their ability to reach therapeutic levels in the CNS. One strategy to minimize antibody fragment clearance is to deliver them slowly or via multiple injections, although this is highly challenging for the treatment of human patients [124]. A second strategy to increase the residency time of these fragments is to link them to an Fc domain $[59,124]$. After 48 hours from infusion in $A D$ transgenic mice, an anti-A $\beta V_{H} H-F c$ exhibited a $40-$ fold higher serum concentration than the isolated $\mathrm{V}_{\mathrm{H}} \mathrm{H}$ fragment [124]. Unfortunately, the brain concentration only increased 4-fold, indicating that inclusion of the Fc domain reduced the brain/blood ratio 10-fold [124]. A third strategy is to bypass peripheral delivery, as intranasal delivery of anti-A $\beta$ scFv slowed amyloid accumulation in AD mice [101]. As single chain proteins, $\mathrm{scFv}$ and $\mathrm{V}_{\mathrm{H}} \mathrm{H}$ domains could also be released continuously via a gene therapy approach using the adeno-associated virus as a vector [101]. While direct central delivery to the brain is not likely to sit well with human patients, intramuscular vector delivery and expression may be a viable option. Expression of anti-A $\beta$ scFv enabled delivery of this drug to the brain over many months, reduced amyloid burden and reversed cognitive impairment in AD mice [101]. While promising, it is unclear whether AD immunotherapy implementation via gene therapy will gain traction in clinical applications.

Trojan Horses. The Trojan horse approach is best defined by genetic engineering of bispecific antibodies. Bispecific antibodies (bsAbs) consist of at least two distinct structural units - one unit which binds a known transporter on the BBB and a second unit which binds the clinical target $[27,84,87,104]$. The target-binding unit is either an intact bivalent IgG [105], presented for monovalent binding by one of the two Fab domains (Figure 1) [160], as a smaller scFv domain [28,141], or nanobody $\mathrm{V}_{\mathrm{H}} \mathrm{H}$ domain [84]. Likewise, the transporter-binding unit is also designed in a variety of forms, ranging from a second IgG antibody domain [27,87], a substitute for one of the two antigen-binding Fab domains (Figure 1) [160], an extra Fab domain [105], or an extra $\mathrm{V}_{\mathrm{H}} \mathrm{H}$ domain [59]. Depending on the bsAb design, a single bsAb can present multiple target-binding units and/or multiple transporter binding units $[84,104]$. In addition, the number of Fc domains can be increased, or removed altogether, to modulate the effector function and bsAb stability $[59,84,104]$.

In the ideal case of $A D$ treatment with bsAbs, the transporter-binding unit binds an endogenous receptor eventually bringing itself and the rest of the bsAb through the BBB and into the brain (Figure 1) $[27,59,87,104,110]$. The two most common transporters used for this purpose are transferrin and insulin $[27,59,87,104,110]$. Once in the brain, the second clinical functionality will bind its target - such as $A \beta$, beta-secretase, or other AD-related target $[105,160]$. A substantial number of bsAbs are in development for a variety of indications and a small number have been approved for use by the FDA [84]. By contrast, bsAbs designed to enhance BBB influx have yet to leave preclinical stages. One issue here is that the transporter-binding unit of most bsAb antibodies for CNS disorders targets the transferrin receptor, a receptor found in many tissues. Although bsAbs are designed to avoid inhibition of transferrin binding, bsAbs targeting the transferrin-receptor have non-negligible toxicity and safety concerns $[39,107]$. Such safety issues may be avoided by targeting transporters found only in BBB endothelium, such as putative receptor $\mathrm{Cdc50A}$ by the $\mathrm{FC} 5 \mathrm{~V}_{\mathrm{H}} \mathrm{H}$ nanobody domain [2,59]. The availability of multiple possible bsAb 
influx routes suggests one will prove successful. Time will tell if bsAbs can benefit AD treatment beyond that of standard antibody therapies.

A second method to produce Trojan Horse antibodies is chemical modification. The ability of covalently-linked synthetic groups to enhance influx of antibodies and other proteins through the BBB has been known for at least two decades [114]. It is hypothesized that this increased brain penetration results from adsorptive endocytosis after binding between the synthetic moieties on the protein with the negatively charged membrane surface or lipid rafts (Figure 1) [104,157]. However, the synthetic groups might also target a specific transporter that enables BBB transport [114]. Regardless of the mechanism, covalent modifications with polyamines and block copolymers have been shown to significantly enhance delivery of antibodies to the brain $[115,157]$. In particular, the BBB penetration of anti-A $\beta$ IgG has been shown to be enhanced 50 -fold by polyamine modification, with minimal change in $A \beta$ binding affinity $[115,119]$. While clearly beneficial in drug delivery, translational efforts have been hindered by an incomplete understanding of its exact chemical nature, safety profile, and mechanism of enhanced action [128].

To overcome these issues, an "in-trans" approach has been developed to deliver large proteins into the brain that does not require chemical modification of the protein [128]. In this strategy, the protein drug is co-injected with a second "carrier" peptide than binds the drug and also targets a receptor on the BBB [128]. A popular carrier peptide for in-trans delivery of both IgG and enzymes is K16ApoE $[99,128]$. K16ApoE consists of 16 lysines, which bind the protein drug, and a domain of ApoE which binds the low density lipoprotein receptor (LDLR) found in the BBB (Figure 1) [128]. Although K16ApoE succeeds in delivering its cargo into the brain, it is toxic at the levels needed for AD treatment [128]. This toxicity will need to be mitigated before this approach can be used in clinical practice.

$B B B$ Disruption. Recent technology advances have enabled ultrasonic pulses that temporarily disrupt targeted sections of the BBB via microbubble cavitation $[33,76,77,89]$. Unlike the specific uptake of modified IgG drugs, this intervention opens the BBB non-specificically, allowing passage of drugs and endogenous proteins alike $[33,76,77,89]$. To maximize drug delivery and mitigate unwanted side-effects, the timing and location of the pulses must be precisely matched to the administration of the drug $[33,76]$. Increased BBB penetration and enhanced clearance of $A \beta$ by an anti-A $\beta$ antibody has been demonstrated in an $A D$ mouse model [76]. Surprisingly, $A \beta$ clearance and cognitive benefits in $A D$ transgenic mice are also reported after ultrasonic pulsing when no drug was administered [77,89]. This finding suggests endogenous proteins may also facilitate $A \beta$ removal in the event of significant $B B B$ disruption $[77,89]$. While clinical trials using this technology have begun for cancer treatment, its effectiveness with AD patients has not yet been shown [33].

\section{$\underline{\text { The neonatal Fc receptor - an endogenous IgG BBB transporter }}$}

The neonatal Fc receptor ( $\mathrm{FcRn}$ ) has been shown to transport IgG in a saturable mechanism across the BBB endothelium $[38,45,162]$. FcRn has been shown to facilitate rapid efflux of excess IgG from the brain after intracerebroventricular administration [38,45,162]. However, its impact on IgG influx and efflux across the BBB is less clear in the context of intravenous administration [34,61]. 
FcRn-mediated influx. IgG influx rates are comparable to that of human serum albumin (HSA) [16,113]. It is notable that albumin has been reported to bind FcRn [127]. However, cross-species binding between mouse FcRn and HSA is weak ( $86 \mathrm{mM}$ ) [5]. Given that picomolar concentrations of radiolabeled HSA are used in BBB studies, it is reasonable to conclude that both IgG and HSA primarily use slow extracellular pathways to cross the BBB under these conditions $[16,113]$.

Supposing that FcRn affects IgG efflux but not influx, a logical conclusion is that FcRn maintains a low brain/blood ratio of IgG. Suprisingly, FcRn knock out mice have the same brain/blood ratio of intraveneously administered antibody as wild-type mice [34,61]. One explanation is that FcRn-mediated efflux is insignificant under typical IgG peripheral delivery conditions, i.e. therapeutic IgG in the brain is zero initially, IgG influx is slow, and IgG recycling is significant. Under these conditions, peripheral therapeutic IgG in FcRn knockout mice would be removed via recycling before these levels reach a significantly higher level in the brain than in wild-type mice. A second explanation is that multiple IgG transporters exist in the BBB that collectively act to maintain an homeostatic brain:plasma equilibrium. In this second scenario, FcRn would contribute to the total rate at which this equilibrium is reached but not the ultimate equilibrium ratio itself. This second model also necessitates that FcRn would exert a small effect on influx to maintain the intrinsic brain:plasma equilibrium.

FcRn-mediated efflux. While even a minor role for FcRn in IgG influx is debatable, the evidence for FcRn in IgG efflux is more significant $[38,45,162]$. Studies have shown that IgG delivered to the brain at high concentrations is rapidly depleted to baseline levels via FcRn $[38,45,162]$. Relative to controls, IgG efflux from the brain is significantly lowered in the context of Fc inhibition [162] , FcRn knock-out [45], and with low-FcRn-affinity IgG [38]. In addition, the level of FcRn in mouse brain endothelial cells (MBECs) is reported to be higher in older mice and Tg2756 AD models [45]. If enhanced IgG efflux is a feature of the aging human brain as well, IgG delivery may be particularly compromised in the population with the greatest need for AD treatments.

In a non-pathological context, IgG efflux may play a role in avoiding aberrant inflammation and immune responses in the brain $[123,130]$. In the context of a CNS disorder, this efflux pathway might either hinder or help IgG-based immunotherapy depending on the clinical mechanism. If a high IgG concentration in the brain was more efficacious, FcRn would hinder treatment by limiting IgG drug accumulation in the brain [123]. If repeated IgG transit into and out of the brain is beneficial, as hypothesized for a peripheral sink mechanism, FcRn could enhance treatment by accelerating the cycling of IgG [63]. Consequently, selective control over this transporter could be highly advantageous in IgG clinical applications.

While conceptually straightforward, modulation of FcRn efflux activity in a patient during IgG drug administration will be highly challenging. One approach is to use FcRn inhibitors such as free Fc domains, protein A constructs, or small engineered peptides [45,46,75,123,162]. However, any such inhibitors would also need to cross the BBB and face the same delivery challenge as the IgG drug they are intended to assist. Additionally, such FcRn inhibitors are also likely to inhibit other FcR species, with many potential complications and side-effects $[68,123]$. 
Another approach is to engineer the IgG therapeutic with reduced FcRn affinity while retaining all other functionalities. Such efforts are difficult as any change to the Fc domain will likely alter the IgG effector function $[1,68]$. It is also possible that influx-enhancing peptides, such as K16ApoE, can be further engineered to also inhibit FcRn efflux [128].

\section{A role for glycosylation in modulating BBB transport of IgG}

All IgG's have a conserved N-linked glycan on N297 of both heavy chains (Figure 2, red and yellow glycans) [68]. In addition, Fab domains can exhibit glycans in the variable regions of either heavy or light chains (Figure 2, magenta glycan) [147]. For a given IgG population, both Fc and Fab glycans are typically highly variable in presentation $[9,29,64,81,112,138,139,147]$. However, those in the Fab domain are more highly processed (longer) that those at the sterically hindered Fc N297 position $[9,44,64,81,85,138,139,147]$. As naturally occurring post-translational modifications, these glycans are not technically defined as chemical modifications of their IgG hosts. Nonetheless, varying the carbohydrate content and linkage chemistry in IgG glycans has direct consequences on their biological activity and therapeutic efficacy $[29,68,81,106,147]$.

For conserved N297 glycans in the Fc domain, there is a general consensus on two aspects of N297 glycosyslation on Fc effector function [68]. First, N297 glycosylation is necessary for FcR binding and activation [68]. Second, trimming of galactose termini on the Fc glycan increases the overall immune response of the IgG, particularly with respect to complement activation [68]. While a novel antiinflammatory role for Fc sialylation has been proposed $[7,79,136]$, this hypothesis has not been supported in studies of its molecular mechanism $[42,139,159]$ and functional outcomes in select disease models $[25,32,64,81,91,108,111,152]$.

In contrast to the relatively well-characterized structure-function relationship of Fc glycans on IgG effector function, the biological role and therapeutic consequences of Fab glycosylation is much more obtuse [147]. The literature provides examples where Fab glycans are correlated with increased antigen affinity $[82,88,142,149,154]$, decreased antigen affinity $[36,88,97,131,154]$, increased aggregation $[71,80,100]$, decreased aggregation [40], increased autoimmune reactivity $[66,122,155,158]$, as well as immunosuppression in the context of autoimmune disease [155], pregnancy [24,29,62,161], B-cell lymphoma [4,98,118,125,131,163], and intravenous immunoglobulin (IVIG) treatment $[81,96,132,133]$. There are also studies that found no correlation between Fab glycosylation and IgG antigen binding [37,125] or therapeutic efficacy of IVIG [32,64,91,108]. This diverse range of findings demonstrates that the effect of a given Fab glycan on biological properties and therapeutic metrics of an IgG drug is difficult to predict. It is also clear that the effects of Fab glycans are highly dependent on glycan carbohydrate composition, glycosidic linkage chemistry, glycosylation residue position in the IgG chain, local IgG sequence near the glycosylation site, and the biological or therapeutic property of interest [147]. Despite this variability, one agreed-upon finding is that sialylation of glycans in Fab, but not Fc, extends the IgG serum half-life $[3,30,37,103]$, presumably due to a lack of interaction with the asialoprotein glycoreceptor in the liver [10].

IgG glycosylation has not been adequately explored with respect to AD immunotherapy. In an effort to develop less inflammatory IgG, one study demonstrated that a deglycosylated mAb engaged $A \beta$ in an AD mouse model equally to that of the parent mAb [153]. Interestingly, the humanization process 
of murine $\mathrm{m} 266$ to produce the therapeutic antibody Solanezumab disrupted a $\mathrm{N}$-glycosylation site in the heavy chain CDR2 [97]. It is not clear if this change was incidental or intentional. Regardless, the therapeutic performance of Solanezumab with human AD patients proved to be much lower than that of m266 with AD mouse models [47,54]. It is possible that this difference is the result of an inadequate mouse model of $A D$ used to study $\mathrm{m} 266$. However, a loss in therapeutic benefit resulting from the missing Fab glycan in Solanezumab cannot presently be dismissed.

Notably absent in the literature is evidence for or against IgG glycan composition as a modulator of BBB influx, efflux, and overall penetration. This gap in knowledge exists for all therapeutic antibodies and not only for antibodies used for $A D$ treatment. However, a number of lines of evidence suggest that glycan modification may enable increased IgG brain penetration and target engagement. A small but consistent set of studies has demonstrated that glycans are an important factor regulating penetration of blood-borne proteins into the brain. A visual summary of this research is presented in Figure 3 . The earliest proteins found to exhibit carbohydrate-mediated BBB transcytosis are lectins, plant proteins with binding specificity for specific carbohydrate termini of glycans [73,92]. At least three lectins have demonstrated increased BBB penetration: wheat germ agglutinin (WGA), Ricin communis agglutinin I (RCAI), and soybean agglutinin (SBA) $[31,70,120]$. Lectins are a natural candidate for influx via adsorptive-mediated transcytosis (AMT) due to their high binding specificity for unique carbohydrate units on glycoproteins and glycolipids in the luminal membrane and glycocalyx of BBB ECs [73]. WGA binds terminal $\mathrm{N}$-acetylglucosamine (GlcNAc) and sialic acid in a variety of glycosidic linkages and can target these groups in the luminal and abluminal membranes of the BBB [70]. RCAI and SBA target galactose and $\mathrm{N}$-acetylgalactosamine groups that are also present in the BBB endothelium [120]. AMT resulting from specific binding of lectins to endothelial carbohydrates represents a distinct AMT pathway from that of polyamines, which bind ECs nonspecifically via electrostatic interactions [114]. Aside from the forces stabilizing membrane binding, further mechanistic differences between AMT of lectins and polyamines, if any, are unclear.

Consistent with its ligand specificity, WGA readily accessed the Golgi transport system of BBB ECs and subsequently entered the CNS via a mechanism consistent with AMT [148] WGA binding to ECs was inhibited by competitive ligands GIcNAc and sialic acid, demonstrating the importance of carbohydrate binding by WGA during its AMT process [120]. Lastly, WGA endocytosis was insensitive to a broad panel of pinocytosis, caveolae-mediated and receptor-mediated transcytosis (RMT) inhibitors [14]. The high affinity, sialic acid- $\alpha 2,6$-galactose specific lectin Sambucus Nigra Agglutinin (SNA) did not exhibit a BBB influx above baseline, suggesting that WGA binds other sialoconjugates, such as $\alpha 2,3$ linkages, on the cell surface (Figure 4) [15]. Interestingly, excess unlabeled WGA did not inhibit radiolabeled WGA influx and instead heightened its influx through the BBB [13]. This positive homotropic behavior is observed in select cases of AMT [53,70] but never with RMT [45,87].

In contrast with WGA, the elevated BBB influx of RCAI was facilitated by $\beta$-D-galactosylcontaining components within caveolae (Figure 3 ) $[70,120]$. The location of this neutral sugar in caveolae is consistent with the absence of negative charge in this region of the EC membrane [70]. Inhibition by free galactose and GalNAc carbohydrates, cell dynamics and endocytosis kinetics, and lack of apparent RMT target support an AMT model for RCAI [120]. A lack of EC surface binding by Dolichos bifuros agglutinin, which binds only $\alpha$-D-galactosyl species, and Jaccalin, which binds only galactose, indicates that RCAI binds $\beta$-D-GalNAc on ECs $[15,120]$. The EC-binding lectin SBA has not been studied to the 
degree WGA and RCAI have [120]. However, its similar ligand-specificity to RCAI and inhibition with a galactose/GIcNAc mixture suggests a similar AMT process as RCAI [120].

A strong case has also been demonstrated for the importance of $\alpha 2,3$-linked sialic acid in an RMT-like influx process the nanobody $\mathrm{FC5}$ through the $\mathrm{BBB}$ [2]. $\mathrm{FC5}$ is a single domain $\mathrm{V}_{\mathrm{H}} \mathrm{H}$ derived from llamas and its binding was optimized to human BBB endothelial cells using phage display $[2,67]$. The effectiveness of clathrin-pit RMT inhibitors identified the dependence of FC5 influx on a novel BBB transporter protein termed Cdc50A, of which few details are known [2,59]. One aspect of Cdc50A that is confirmed is that it exhibits surface-accessible $\alpha 2,3$-linked sialic acid groups (illustrated in Figure 4) and that binding of FC5 to these groups is necessary for the RMT-like influx of Fc5 [2].

A different case of carbohydrate-mediated BBB transcytosis is found with the HIV coat glycoprotein gp120 [14]. As with WGA and RCAI, gp120 also appears to exhibit increased brain penetration due to AMT. However its initial binding event differs from that of these lectins. The initial binding of WGA, RCAI, and SBA to ECs all occur via the binding site on the lectin and a carbohydrate ligand on ECs $[13,31,120]$. By contrast, a glycan carbohydrate on gp120 binds a protein site on the surface of ECs to facilitate AMT $[14,15,18,53]$. Thus, carbohydrates expressed on either the free protein or the BBB can mediate BBB influx.

Gp120 exhibits a significant BBB influx rate that cannot not be explained with paracellular pathways [14]. Although gp120 is not a lectin, both WGA and RCAl lectins stimulated the gp120 influx rate and brain penetration $[14,15]$. This effect was similar to the ability of WGA to self-stimulate its own

AMT rate [13]. However, addition of unlabeled gp120 did not alter the transcystosis rate of radiolabeled gp120 [15]. Together these findings suggest (1) different, but additive, lectin and gp120 AMT mechanisms and/or (2) stronger AMT processes induced by the lectins than by gp120 [15]. The stimulatory effect of WGA was significantly higher than RCAl suggesting that gp120 bound ECs in regions closer to sialoconjugates than caveolae (Figure 3) [15]. The importance of gp120 glycans was demonstrated when both the influx of gp120 and its enhancement by WGA was eliminated by gp120 deglycosylation [15]. A more recent study implicated high mannose glycans on gp120 since HIV BBB permeability was reduced by mannose-6-phosphate inhibition, mannan inhibition, and enzymatic cleavage of HIV high mannose glycan receptors [53]. This same study also supported an interaction between other components of the HIV viral coat and heparin components of the EC glycocalyx, which could also be mediated via carbohydrates [53].

The implications of the BBB studies with lectins and gp120 for AD immunotherapy with IgG are two-fold. First endogenous IgG that either bind or present surface glycans might be capable of access to the brain parenchyma at higher levels than those lacking such groups. Presumably, IgG tested in prior BBB studies do not exhibit such glycosylation groups $[16,113]$. Second, engineered glycosylation could be used as a minimally perturbative method to increase the BBB penetration of therapeutic antibodies for AD. Given that Fc glycans are less sterically accessible than Fab glycans, efforts to add glycans to IgG would focus on sites in the Fab domain $[64,81,139]$. Nonetheless, it may be possible for two fully processed Fc glycans to become surface accessible $[139,150]$. Fc glycosylation may also modulate the Fc structure such that BBB penetration is altered via Fc-mediated interactions, such as that with FcRn [45].

The high mannose glycans responsible for increased gp120 BBB influx are rare on typical IgG $[29,138]$. However, evidence suggests that other antibody glycans can also modulate BBB transport. One 
indirect piece of evidence for this hypothesis is that antibodies of the same class and antigen specificity exhibit significantly different rates of BBB influx and efflux $[12,19]$. A comparison of the BBB kinetics of anti-A $\beta$ mouse monoclonal antibodies $4 G 8$ and $6 E 10$ in APP23 mice found both influx and efflux rates to be faster for $6 E 10$ than for $4 G 8$ [12]. In addition, the influx and efflux of polyclonal human anti-A $\beta$ antibodies was slower than either 4G8 or 6E10 [12]. All these antibody isotypes and subclasses bind $A \beta$ antigens and mouse FcRn with comparable affinity $[41,119,123]$. Thus, additional factors are necessary to explain the differences in BBB transport between these similar IgG species.

A recent study has demonstrated significant differences in surface presentation of glycoconjugates between $6 \mathrm{E} 10,4 \mathrm{G} 8$, and polyclonal human anti-A $\beta$ IgG in intravenous immunoglobulin (IVIG) [85]. Mouse IgG1 6E10 was devoid of glycans other than the Fc glycan, and this glycan was predominantly (>95\%) unsialylated [85]. By contrast, mouse IgG2b $4 \mathrm{G} 8$ has a significant fraction of light chain Fab domains with a glycan that retains the conventional $\alpha 2,6$ sialic acid terminal groups [85]. 4G8 Fc sialyation was not detected and removal of the Fc glycan had no effect on surface sialic acid presentation and lectin binding [85]. Interestingly, human anti-A $\beta$ IgG from IVIG exhibited a significant amount of surface glycans with sialic acid in an non- $\alpha 2,6$ linkage with galactose [85]. These differences in surface glycan composition may account for the differences in BBB transport rates observed between these IgG species in the in vivo mouse study [12].

In vitro studies in our labs have confirmed that the addition of surface accessible sialic acid on IgG glycans reduces IgG efflux, although no effect on influx was observed (in press). Removal of the Fc glycan partially restores the IgG efflux capability, indicating that Fab sialylation plays a role in this inhibitory effect but that the Fc glycan is an important factor as well. Interestingly, this efflux was highly inhibited even though only $15 \%$ of IgG in the sialylated preparation actually presented surface-accessible sialic acid (in press). Given that Fc sialylation was negligible in 4G8, we posit that sialylated IgG inhibits the efflux of unsialylated IgG (Figure 5). An inhibitory effect between sialylated IgG and other unsialylated proteins, including other IgG, remains to be determined.

Prior studies have implicated FcRn as a significant IgG efflux transporter in the BBB $[38,45,130]$. It is therefore possible that FcRn is the efflux transporter inhibited by sialylated 4G8. If so, this inhibition would occur under picomolar concentrations of sialylated $4 \mathrm{G} 8$. While this hypothesis is tantalizingly simple, the actual mode of action may be more complicated. First, sialylated IgG has generally shown to have an FcyR affinity that is equal to or less favorable than non-sialylated IgG [8]. Second, the removal of sialic acid from IVIG and Fc has not been shown to alter its ability to faciliate FcRn blockade in rheumatic arthritis animal models [111]. Lastly, sialic acid on glycoproteins is known to bind a range of endogenous and exogenous proteins $[6,10,30,60]$ and also impairs IgG binding to natural ligands $[36,88]$. These interactions may inhibit IgG efflux pathways that are independent of FcRn-mediated transcytosis.

It should be noted that the surface sialic acid in IgG, when present, is predominantly associated with glycans in the Fab domains $[9,44,64,81,85,138,139,147]$. This Fab domain permits a large variation in possible presentations of this sialic acid. Thus, binding between Fab sialic acid and other biomolecules can vary drastically depending on steric bioavailability, local primary sequence, and non-local tertiary IgG structure around the glycosylation site presenting the sialic acid [147]. In an optimal context, the affinity of Fab-sialylated IgG could be significantly higher than the Fc domain for FcRn or other BBB transporters. While intriguing, the thermodynamics of such factors in surface-sialylated IgG inhibitory 
binding to RcRn or other transporters is presently unexplored. Further work is needed to adequately understand the connection between IgG sialic acid and BBB efflux.

\section{Therapeutic considerations: Is more always better?}

Regardless of which strategies gain traction in academic labs and the pharmaceutical industry to increase antibody blood-brain barrier penetration, a key factor will be control. Given our current inability to deliver antibodies to the brain, a pro and con debate over the merits of delivering high doses to the brain might seem counterproductive. However, the root causes of AD remain unclear $[26,63,90,102]$. While the amyloid hypothesis continues to be the leading model of AD pathology, this does not preclude other pathological contributions, such as inflammation, as contributors to AD [69]. If so, antibody drugs may need to be delivered to the brain within a narrow concentration range that balances the benefits of $\beta$-amyloid elimination with the potential complications of inflammation [69]. Achieving this optimal concentration is best achieved with a BBB delivery method that can be readily modulated to achieve optimal therapeutic efficacy. A "toolbox" of different transporter-binding proteins or chemical moieties with a range of defined BBB penetration capabilities would be ideal.

Most monoclonal therapeutic antibodies for AD are immune system agonists that are intended to activate effector function ligands after binding their target [97]. However, an alternate antibody drug used to treat AD is IVIG, which is typically used as an immune system antagonist to treat autoimmune conditions $[43,117,137,146]$. Somewhat contradictory to its prescribed applications, the justification for IVIG treatment of $A D$ was the presence of anti-A $\beta$ IgG in IVIG and the lack of such antibodies in AD patients $[49,55,151]$. This anti-A $\beta$ IgG component of IVIG may prove beneficial as its specificity for oligomeric/fibrillar $A \beta$, but not monomeric $A \beta$, is similar to the promising drug aducanumab $[41,50,119,134]$. However, the high doses used in AD clinical trials (> $100 \mathrm{mg} / \mathrm{kg}$ ) are more consistent with immunosuppressive IVIG applications [51,86]. IVIG does provide immune protection for immunecompromised individuals when applied at low doses [116,145]. But higher doses of IVIG were used in AD clinical trials $[51,86]$. Thus, inflammatory pathways, if present, were suppressed during IVIG treatment of AD patients. Given the small possible benefit of IVIG reported for AD patients at the higher doses, one cannot rule out a beneficial role for immune system suppression in AD treatment [86].

It is notable that sialic acid, posited to increase BBB penetration, has also been proposed as an anti-inflammatory moiety in IVIG $[7,79,136]$. This hypothesis originally focused exclusively on Fc sialylation and has since received considerable debate in the literature $[25,32,64,81,91,108,111,152]$. In addition to this putative anti-inflammatory role of Fc sialylation, Fab glycan sialylation has also exhibited anti-inflammatory effects in mouse models and in clinical settings $[81,106]$. At present, the therapeutic significance of different glycoforms and linkage sites in therapeutic IgG remains untested with AD. Moving forward, a strong argument can be made for investigating anti-A $\beta$ IgG modifications that increase BBB penetration and also provide other potential therapeutic benefits, such as a reduction in harmful inflammatory side-effects. 
Figures

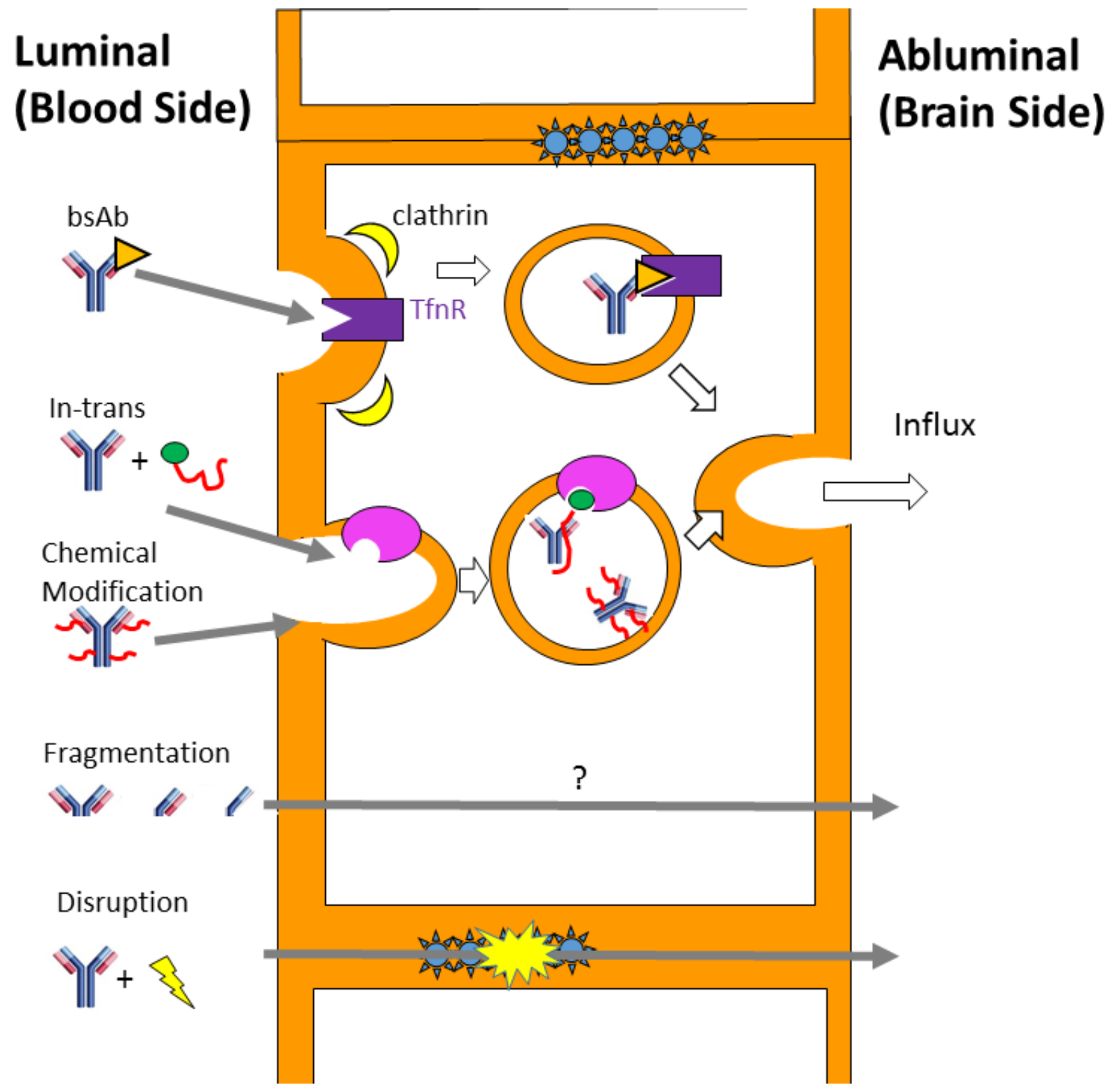

Figure 1. Current methods to increase IgG influx are shown: (1) bispecific antibodies that target receptors such as Transferrin Receptor ( $T f n R$ ) and induce receptor-mediated transcytosis (RMT); (2) induction of adsorptive-mediated transcytosis (AMT) via in-trans delivery of IgG along with small peptides that bind both IgG and the a BBB component; (3) induction of AMT via chemically modified IgG that bind the BBB endothelium; (4) reduction in size of IgG via unknown mechanism(s); (5) targeted disruption of the BBB with ultrasonic pulses during IgG administration. 

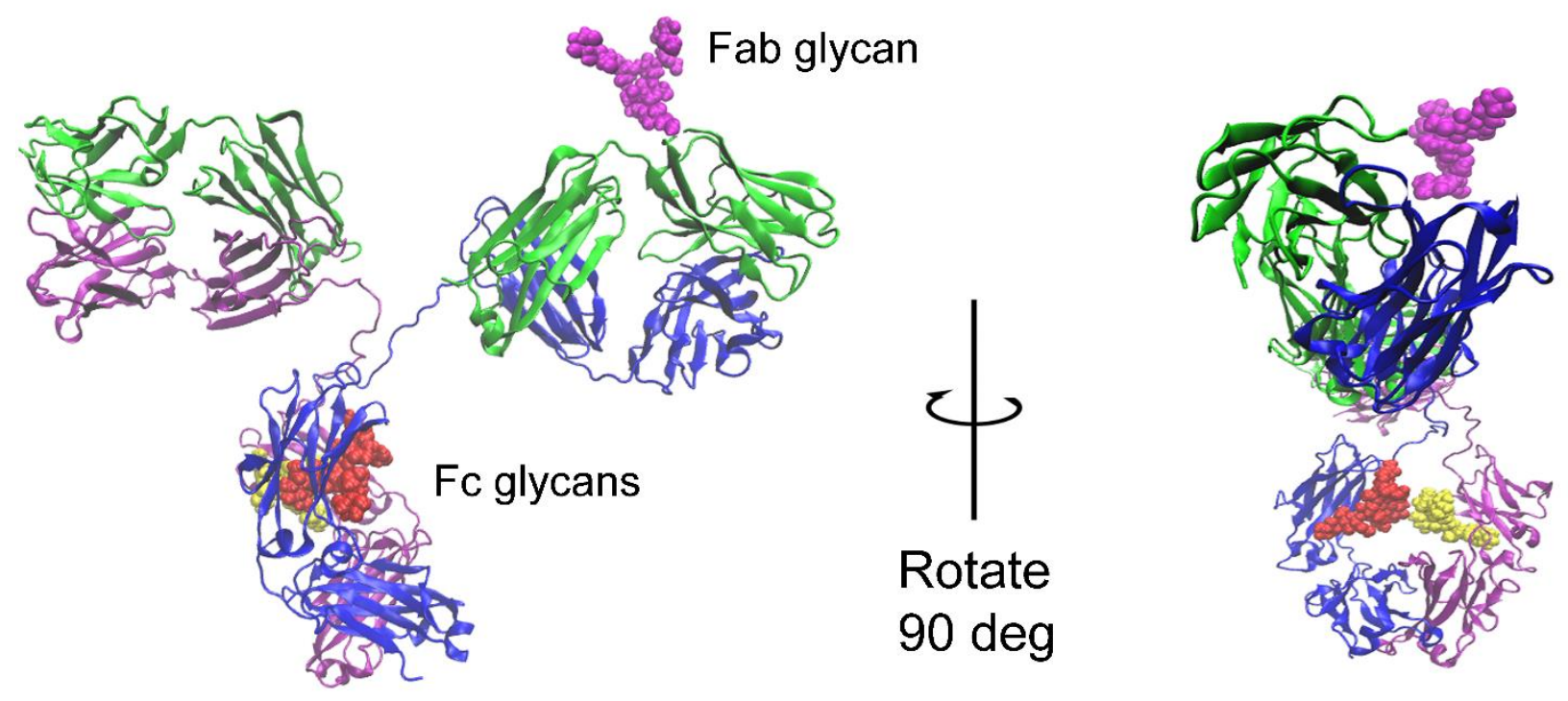

Figure 2. Structure of IgG showing the common location and structure of both Fc glycans (red and yellow atoms) and one possible location and structure of a single Fab glycan (magenta atoms). The structure shown from two angles to highlight the Fab glycan (left) and Fc glycans (right). 


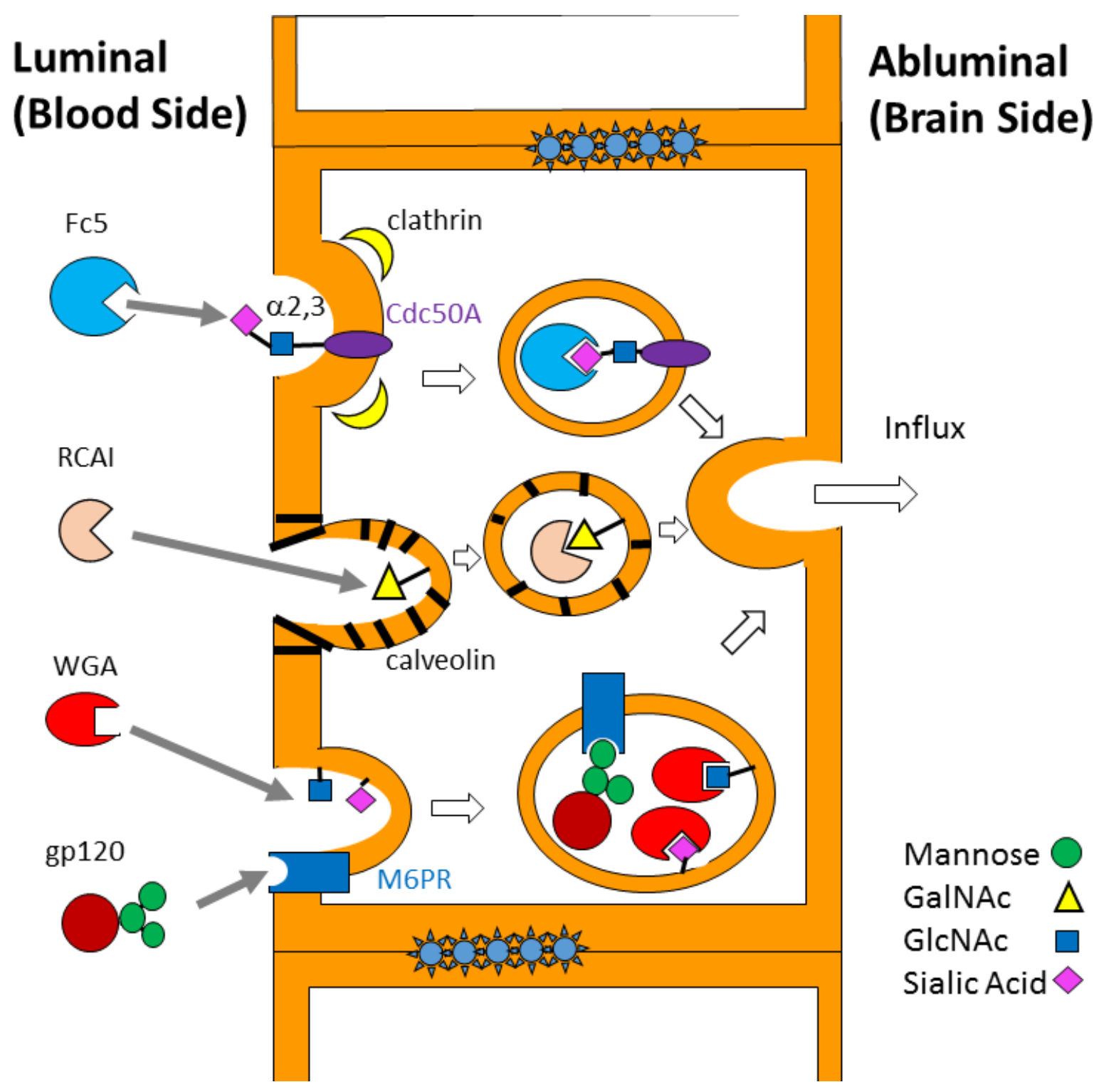

Figure 3. Summary of carbohydrate-dependent BBB influx pathways found in the literature: (1) The engineered $\mathrm{V}_{\mathrm{H}} \mathrm{H}$ nanobody $\mathrm{FC5}$ binds a2,3-linked sialic acid on a largely unknown protein Cdc50A and is delivered to the brain through a process resembling RMT; (2) The lectin Ricin Communnis Agglutinin I (RCAI) binds $\mathrm{N}$-acetylgalactosamine found in the EC luminal membrane and is transported via AMT(; (3) The lectin wheat germ agglutinin (WGA) induces AMT through binding of exposed N-acetylglucosamine and/or sialic acid carbohydrates on the BBB endothelium; (4) gp120 presents mannose groups that can bind the mannose-6-phosphate receptor (M6PR) and thereby weakly induce AMT. WGA and gp120 have a high overlap in their access of endosomal pathways, presumably due to proximity of GlcNAc/sialic acid and M6PR. 
A

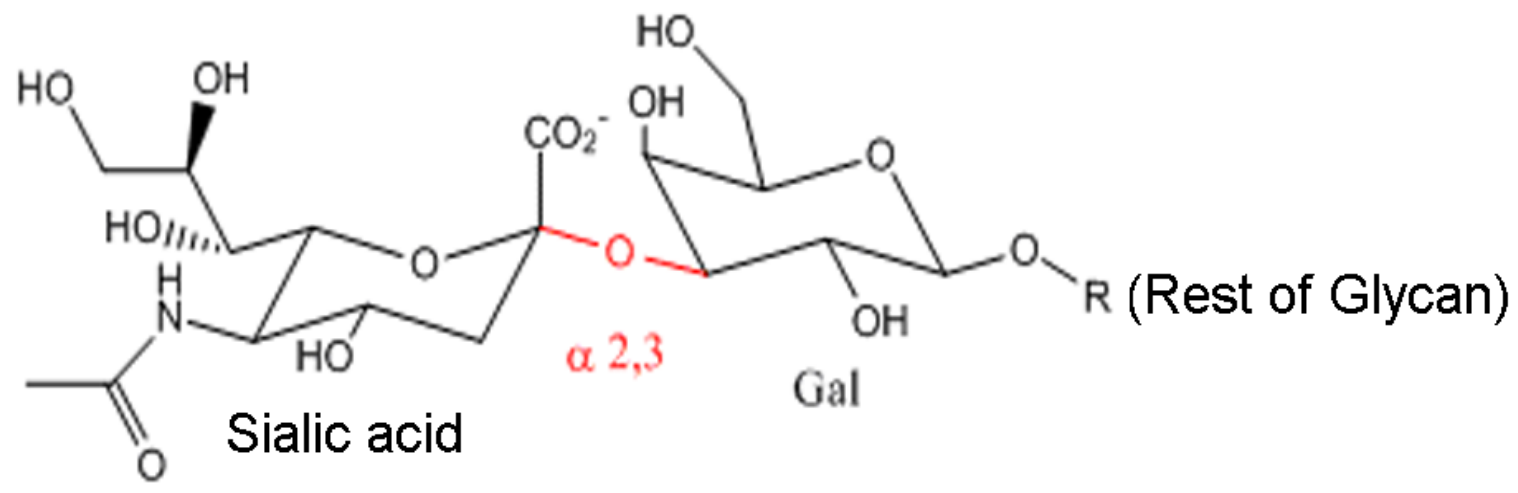

B

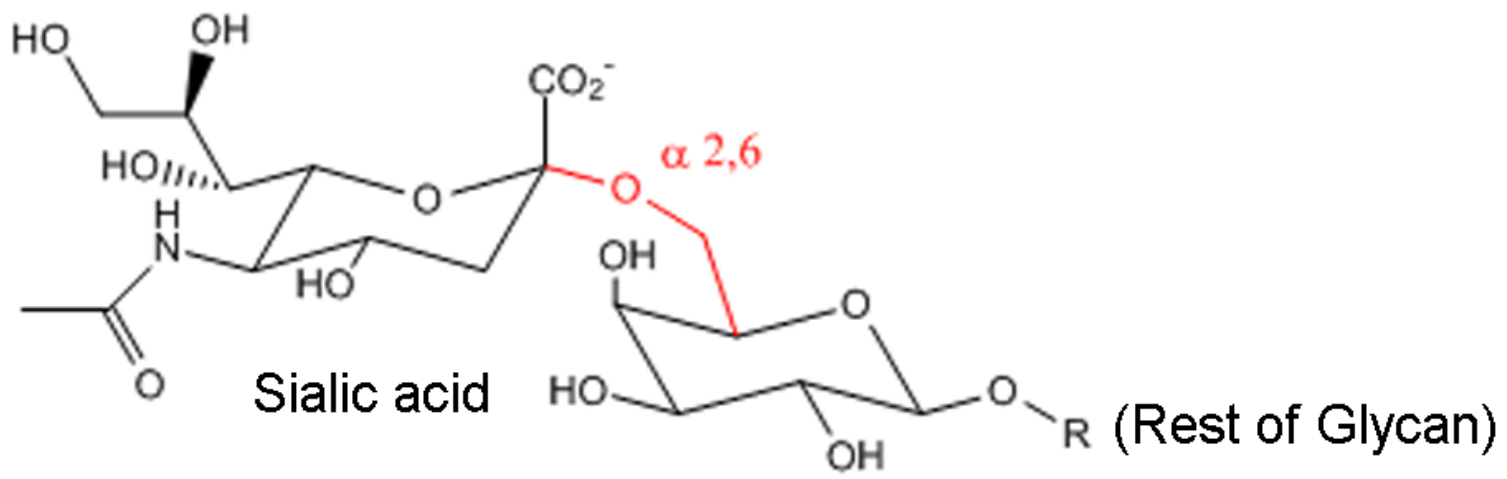

Gal

Figure 4. Chemical structure of the (A) $\alpha 2,3$ galactose-sialic acid bond linkage and (B) $\alpha 2,6$ galactosesialic acid bond linkage. 


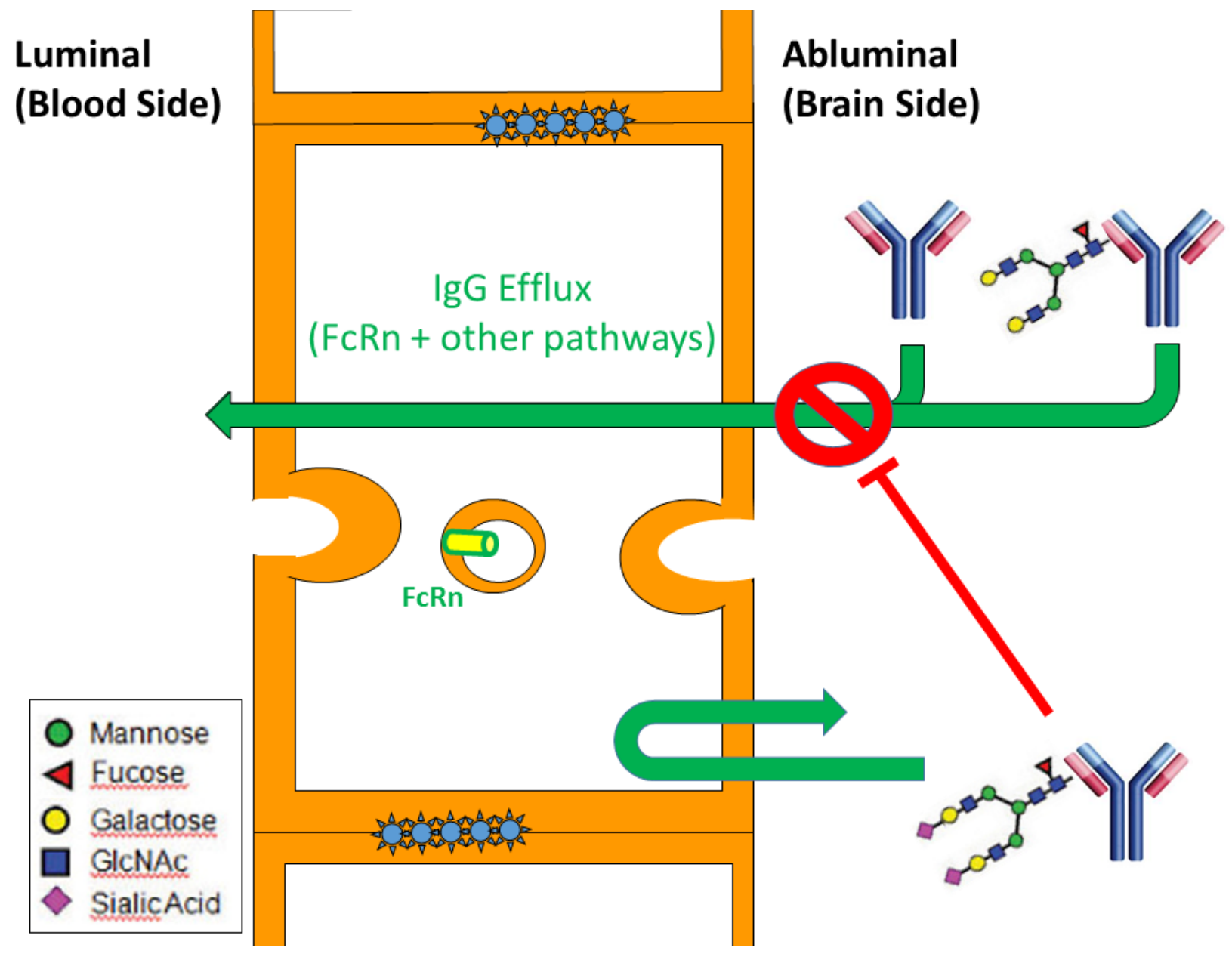

Figure 5. Proposed action of sialylated Fab glycan in $4 \mathrm{G} 8 \mathrm{IgG}$. Sialylation prevents both the sialylated $4 \mathrm{G} 8$ to efflux and also inhibits efflux of other non-sialylated forms of $4 \mathrm{G} 8$. 
1. R.C. Aalberse, and J. Schuurman, IgG4 breaking the rules, Immunology 105 (2002), 9-19.

2. A. Abulrob, H. Sprong, P. Van Bergen en Henegouwen, and D. Stanimirovic, The blood-brain barrier transmigrating single domain antibody: mechanisms of transport and antigenic epitopes in human brain endothelial cells, J Neurochem 95 (2005), 1201-1214.

3. L. Alessandri, D. Ouellette, A. Acquah, M. Rieser, D. LeBlond, M. Saltarelli, C. Radziejewski, T. Fujimori, and I. Correia, Increased serum clearance of oligomannose species present on a human IgG1 molecule, Mabs 4 (2012), 509-520.

4. R. Amin, F. Mourcin, F. Uhel, C. Pangault, P. Ruminy, L. Dupre, M. Guirriec, T. Marchand, T. Fest, T. Lamy, and K. Tarte, DC-SIGN-expressing macrophages trigger activation of mannosylated IgM B-cell receptor in follicular lymphoma, Blood 126 (2015), 1911-1920.

5. J.T. Andersen, M.B. Daba, G. Berntzen, T.E. Michaelsen, and I. Sandlie, Cross-species binding analyses of mouse and human neonatal Fc receptor show dramatic differences in immunoglobulin G and albumin binding, J Biol Chem 285 (2010), 4826-4836.

6. T. Angata, S.C. Kerr, D.R. Greaves, N.M. Varki, P.R. Crocker, and A. Varki, Cloning and characterization of human Siglec-11. A recently evolved signaling molecule that can interact with SHP-1 and SHP-2 and is expressed by tissue macrophages, including brain microglia, J Biol Chem 277 (2002), 24466-24474.

7. R.M. Anthony, F. Nimmerjahn, D.J. Ashline, V.N. Reinhold, J.C. Paulson, and J.V. Ravetch, Recapitulation of IVIG anti-inflammatory activity with a recombinant IgG Fc, Science 320 (2008), 373-376.

8. R.M. Anthony, F. Wermeling, and J.V. Ravetch, Novel roles for the IgG Fc glycan, Ann N Y Acad Sci 1253 (2012), 170-180.

9. K.R. Anumula, Quantitative glycan profiling of normal human plasma derived immunoglobulin and its fragments Fab and Fc, J Immunol Methods 382 (2012), 167-176.

10. G. Ashwell, and A.G. Morell, ROLE OF SURFACE CARBOHYDRATES IN HEPATIC RECOGNITION AND TRANSPORT OF CIRCULATING GLYCOPROTEINS, Advances in Enzymology and Related Areas of Molecular Biology 41 (1974), 99-128.

11. J.K. Atwal, Y. Chen, C. Chiu, D.L. Mortensen, W.J. Meilandt, Y. Liu, C.E. Heise, K. Hoyte, W. Luk, Y. Lu, K. Peng, P. Wu, L. Rouge, Y. Zhang, R.A. Lazarus, K. Scearce-Levie, W. Wang, Y. Wu, M. Tessier-Lavigne, and R.J. Watts, A therapeutic antibody targeting BACE1 inhibits amyloid-beta production in vivo, Sci Transl Med 3 (2011), 84ra43.

12. M. Bacher, C. Depboylu, Y. Du, C. Noelker, W.H. Oertel, T. Behr, G. Henriksen, M. Behe, and R. Dodel, Peripheral and central biodistribution of (111)In-labeled anti-beta-amyloid autoantibodies in a transgenic mouse model of Alzheimer's disease, Neurosci Lett 449 (2009), 240-245.

13. W.A. Banks, and R.D. Broadwell, Blood to brain and brain to blood passage of native horseradish peroxidase, wheat germ agglutinin, and albumin: pharmacokinetic and morphological assessments, J Neurochem 62 (1994), 2404-2419.

14. W.A. Banks, A.J. Kastin, and V. Akerstrom, HIV-1 protein gp120 crosses the blood-brain barrier: role of adsorptive endocytosis, Life Sci 61 (1997), PL119-125.

15. W.A. Banks, and A.J. Kastin, Characterization of lectin-mediated brain uptake of HIV-1 GP120, J Neurosci Res 54 (1998), 522-529.

16. W.A. Banks, B. Terrell, S.A. Farr, S.M. Robinson, N. Nonaka, and J.E. Morley, Passage of amyloid beta protein antibody across the blood-brain barrier in a mouse model of Alzheimer's disease, Peptides 23 (2002), 2223-2226.

17. W.A. Banks, Are the extracellular [correction of extracelluar] pathways a conduit for the delivery of therapeutics to the brain?, Curr Pharm Des 10 (2004), 1365-1370. 
18. W.A. Banks, S.M. Robinson, K.M. Wolf, J.W. Bess, Jr., and L.O. Arthur, Binding, internalization, and membrane incorporation of human immunodeficiency virus-1 at the blood-brain barrier is differentially regulated, Neuroscience 128 (2004), 143-153.

19. W.A. Banks, S.A. Farr, J.E. Morley, K.M. Wolf, V. Geylis, and M. Steinitz, Anti-amyloid beta protein antibody passage across the blood-brain barrier in the SAMP8 mouse model of Alzheimer's disease: an age-related selective uptake with reversal of learning impairment, Exp Neurol 206 (2007), 248-256.

20. W.A. Banks, Immunotherapy and neuroimmunology in Alzheimer's disease: a perspective from the blood-brain barrier, Immunotherapy 2 (2010), 1-3.

21. W.A. Banks, A.M. Gray, M.A. Erickson, T.S. Salameh, M. Damodarasamy, N. Sheibani, J.S. Meabon, E.E. Wing, Y. Morofuji, D.G. Cook, and M.J. Reed, Lipopolysaccharide-induced bloodbrain barrier disruption: roles of cyclooxygenase, oxidative stress, neuroinflammation, and elements of the neurovascular unit, J Neuroinflammation 12 (2015), 223.

22. W.A. Banks, From blood-brain barrier to blood-brain interface: new opportunities for CNS drug delivery, Nat Rev Drug Discov 15 (2016), 275-292.

23. F. Bard, C. Cannon, R. Barbour, R.L. Burke, D. Games, H. Grajeda, T. Guido, K. Hu, J. Huang, K. Johnson-Wood, K. Khan, D. Kholodenko, M. Lee, I. Lieberburg, R. Motter, M. Nguyen, F. Soriano, N. Vasquez, K. Weiss, B. Welch, P. Seubert, D. Schenk, and T. Yednock, Peripherally administered antibodies against amyloid beta-peptide enter the central nervous system and reduce pathology in a mouse model of Alzheimer disease, Nat Med 6 (2000), 916-919.

24. G. Barrientos, D. Fuchs, K. Schroecksnadel, M. Ruecke, M.G. Garcia, B.F. Klapp, R. Raghupathy, S. Miranda, P.C. Arck, and S.M. Blois, Low levels of serum asymmetric antibodies as a marker of threatened pregnancy, Journal of Reproductive Immunology 79 (2009), 201-210.

25. J. Bayry, K. Bansal, M.D. Kazatchkine, and S.V. Kaveri, DC-SIGN and alpha 2,6-sialylated IgG Fc interaction is dispensable for the anti-inflammatory activity of IVIg on human dendritic cells, Proceedings of the National Academy of Sciences of the United States of America 106 (2009), E24-E24.

26. I. Benilova, E. Karran, and B. De Strooper, The toxic Abeta oligomer and Alzheimer's disease: an emperor in need of clothes, Nat Neurosci 15 (2012), 349-357.

27. U. Bickel, T. Yoshikawa, and W.M. Pardridge, Delivery of peptides and proteins through the blood-brain barrier, Adv Drug Deliv Rev 46 (2001), 247-279.

28. R.J. Boado, Y. Zhang, Y. Zhang, C.F. Xia, and W.M. Pardridge, Fusion antibody for Alzheimer's disease with bidirectional transport across the blood-brain barrier and abeta fibril disaggregation, Bioconjug Chem 18 (2007), 447-455.

29. A. Bondt, Y. Rombouts, M.H. Selman, P.J. Hensbergen, K.R. Reiding, J.M. Hazes, R.J. Dolhain, and M. Wuhrer, Immunoglobulin G (IgG) Fab glycosylation analysis using a new mass spectrometric high-throughput profiling method reveals pregnancy-associated changes, Mol Cell Proteomics 13 (2014), 3029-3039.

30. K. Bork, R. Horstkorte, and W. Weidemann, Increasing the Sialylation of Therapeutic Glycoproteins: The Potential of the Sialic Acid Biosynthetic Pathway, Journal of Pharmaceutical Sciences 98 (2009), 3499-3508.

31. R.D. Broadwell, B.J. Balin, and M. Salcman, Transcytotic pathway for blood-borne protein through the blood-brain barrier, Proc Natl Acad Sci U S A 85 (1988), 632-636.

32. I.K. Campbell, S. Miescher, D.R. Branch, P.J. Mott, A.H. Lazarus, D. Han, E. Maraskovsky, A.W. Zuercher, A. Neschadim, D. Leontyev, B.S. McKenzie, and F. Kasermann, Therapeutic effect of IVIG on inflammatory arthritis in mice is dependent on the Fc portion and independent of sialylation or basophils, J Immunol 192 (2014), 5031-5038. 
33. A. Carpentier, M. Canney, A. Vignot, V. Reina, K. Beccaria, C. Horodyckid, C. Karachi, D. Leclercq, C. Lafon, J.Y. Chapelon, L. Capelle, P. Cornu, M. Sanson, K. Hoang-Xuan, J.Y. Delattre, and A. Idbaih, Clinical trial of blood-brain barrier disruption by pulsed ultrasound, Sci Trans/ Med 8 (2016), 343re342.

34. N. Chen, W. Wang, S. Fauty, Y. Fang, L. Hamuro, A. Hussain, and T. Prueksaritanont, The effect of the neonatal Fc receptor on human IgG biodistribution in mice, MAbs 6 (2014), 502-508.

35. Z. Cheng, J. Zhang, H. Liu, Y. Li, Y. Zhao, and E. Yang, Central nervous system penetration for small molecule therapeutic agents does not increase in multiple sclerosis- and Alzheimer's disease-related animal models despite reported blood-brain barrier disruption, Drug Metab Dispos 38 (2010), 1355-1361.

36. M.S. Co, D.A. Scheinberg, N.M. Avdalovic, K. McGraw, M. Vasquez, P.C. Caron, and C. Queen, GENETICALLY-ENGINEERED DEGLYCOSYLATION OF THE VARIABLE DOMAIN INCREASES THE AFFINITY OF AN ANTI-CD33 MONOCLONAL-ANTIBODY, Molecular Immunology 30 (1993), 1361\&.

37. M.J. Coloma, R.K. Trinh, A.R. Martinez, and S.L. Morrison, Position effects of variable region carbohydrate on the affinity and in vivo behavior of an anti-(1 ->6) dextran antibody, Journal of Immunology 162 (1999), 2162-2170.

38. P.R. Cooper, G.J. Ciambrone, C.M. Kliwinski, E. Maze, L. Johnson, Q. Li, Y. Feng, and P.J. Hornby, Efflux of monoclonal antibodies from rat brain by neonatal Fc receptor, FcRn, Brain Res 1534 (2013), 13-21.

39. J.A. Couch, Y.J. Yu, Y. Zhang, J.M. Tarrant, R.N. Fuji, W.J. Meilandt, H. Solanoy, R.K. Tong, K. Hoyte, W. Luk, Y. Lu, K. Gadkar, S. Prabhu, B.A. Ordonia, Q. Nguyen, Y. Lin, Z. Lin, M. Balazs, K. Scearce-Levie, J.A. Ernst, M.S. Dennis, and R.J. Watts, Addressing safety liabilities of TfR bispecific antibodies that cross the blood-brain barrier, Sci Transl Med 5 (2013), 183ra157, 181112.

40. F. Courtois, N.J. Agrawal, T.M. Lauer, and B.L. Trout, Rational design of therapeutic mAbs against aggregation through protein engineering and incorporation of glycosylation motifs applied to bevacizumab, Mabs 8 (2016), 99-112.

41. A.C. Crisostomo, L. Dang, J.L. Digambaranath, A.C. Klaver, D.A. Loeffler, J.J. Payne, L.M. Smith, A.L. Yokom, and J.M. Finke, Kinetic analysis of IgG antibodies to beta-amyloid oligomers with surface plasmon resonance, Anal Biochem 481 (2015), 43-54.

42. M. Crispin, X. Yu, and T.A. Bowden, Crystal structure of sialylated IgG Fc: implications for the mechanism of intravenous immunoglobulin therapy, Proc Natl Acad Sci U S A 110 (2013), E35443546.

43. M.C. Dalakas, Intravenous immunoglobulin in autoimmune neuromuscular diseases, JAMA 291 (2004), 2367-2375.

44. M. Dalziel, I. McFarlane, and J.S. Axford, Lectin analysis of human immunoglobulin G N-glycan sialylation, Glycoconjugate Journal 16 (1999), 801-807.

45. R. Deane, A. Sagare, K. Hamm, M. Parisi, B. LaRue, H. Guo, Z. Wu, D.M. Holtzman, and B.V. Zlokovic, IgG-assisted age-dependent clearance of Alzheimer's amyloid beta peptide by the blood-brain barrier neonatal Fc receptor, J Neurosci 25 (2005), 11495-11503.

46. W.L. DeLano, M.H. Ultsch, A.M. de Vos, and J.A. Wells, Convergent solutions to binding at a protein-protein interface, Science 287 (2000), 1279-1283.

47. R.B. DeMattos, K.R. Bales, D.J. Cummins, J.C. Dodart, S.M. Paul, and D.M. Holtzman, Peripheral anti-A beta antibody alters CNS and plasma $A$ beta clearance and decreases brain $A$ beta burden in a mouse model of Alzheimer's disease, Proc Natl Acad Sci U S A 98 (2001), 8850-8855. 
48. D.L. Dickstein, K.E. Biron, M. Ujiie, C.G. Pfeifer, A.R. Jeffries, and W.A. Jefferies, Abeta peptide immunization restores blood-brain barrier integrity in Alzheimer disease, FASEB J 20 (2006), 426-433.

49. R. Dodel, H. Hampel, C. Depboylu, S. Lin, F. Gao, S. Schock, S. Jackel, X. Wei, K. Buerger, C. Hoft, B. Hemmer, H.J. Moller, M. Farlow, W.H. Oertel, N. Sommer, and Y. Du, Human antibodies against amyloid beta peptide: a potential treatment for Alzheimer's disease, Ann Neurol $\mathbf{5 2}$ (2002), 253-256.

50. R. Dodel, K. Balakrishnan, K. Keyvani, O. Deuster, F. Neff, L.C. Andrei-Selmer, S. Roskam, C. Stuer, Y. Al-Abed, C. Noelker, M. Balzer-Geldsetzer, W. Oertel, Y. Du, and M. Bacher, Naturally occurring autoantibodies against beta-amyloid: investigating their role in transgenic animal and in vitro models of Alzheimer's disease, J Neurosci 31 (2011), 5847-5854.

51. R. Dodel, A. Rominger, P. Bartenstein, F. Barkhof, K. Blennow, S. Forster, Y. Winter, J.P. Bach, J. Popp, J. Alferink, J. Wiltfang, K. Buerger, M. Otto, P. Antuono, M. Jacoby, R. Richter, J. Stevens, I. Melamed, J. Goldstein, S. Haag, S. Wietek, M. Farlow, and F. Jessen, Intravenous immunoglobulin for treatment of mild-to-moderate Alzheimer's disease: a phase 2, randomised, double-blind, placebo-controlled, dose-finding trial, Lancet Neurol 12 (2013), 233-243.

52. R.C. Dodel, Y. Du, C. Depboylu, H. Hampel, L. Frolich, A. Haag, U. Hemmeter, S. Paulsen, S.J. Teipel, S. Brettschneider, A. Spottke, C. Nolker, H.J. Moller, X. Wei, M. Farlow, N. Sommer, and W.H. Oertel, Intravenous immunoglobulins containing antibodies against beta-amyloid for the treatment of Alzheimer's disease, J Neurol Neurosurg Psychiatry 75 (2004), 1472-1474.

53. S. Dohgu, J.S. Ryerse, S.M. Robinson, and W.A. Banks, Human immunodeficiency virus-1 uses the mannose-6-phosphate receptor to cross the blood-brain barrier, PLoS One 7 (2012), e39565.

54. R.S. Doody, R.G. Thomas, M. Farlow, T. Iwatsubo, B. Vellas, S. Joffe, K. Kieburtz, R. Raman, X. Sun, P.S. Aisen, E. Siemers, H. Liu-Seifert, R. Mohs, C. Alzheimer's Disease Cooperative Study Steering, and G. Solanezumab Study, Phase 3 trials of solanezumab for mild-to-moderate Alzheimer's disease, N Engl J Med 370 (2014), 311-321.

55. Y. Du, R. Dodel, H. Hampel, K. Buerger, S. Lin, B. Eastwood, K. Bales, F. Gao, H.J. Moeller, W. Oertel, M. Farlow, and S. Paul, Reduced levels of amyloid beta-peptide antibody in Alzheimer disease, Neurology 57 (2001), 801-805.

56. I. Elovaara, A. Icen, J. Palo, and T. Erkinjuntti, CSF in Alzheimer's disease. Studies on blood-brain barrier function and intrathecal protein synthesis, J Neurol Sci 70 (1985), 73-80.

57. M.A. Erickson, and W.A. Banks, Blood-brain barrier dysfunction as a cause and consequence of Alzheimer's disease, J Cereb Blood Flow Metab 33 (2013), 1500-1513.

58. A.J. Farrall, and J.M. Wardlaw, Blood-brain barrier: ageing and microvascular disease--systematic review and meta-analysis, Neurobiol Aging 30 (2009), 337-352.

59. G.K. Farrington, N. Caram-Salas, A.S. Haqqani, E. Brunette, J. Eldredge, B. Pepinsky, G. Antognetti, E. Baumann, W. Ding, E. Garber, S. Jiang, C. Delaney, E. Boileau, W.P. Sisk, and D.B. Stanimirovic, A novel platform for engineering blood-brain barrier-crossing bispecific biologics, FASEB J 28 (2014), 4764-4778.

60. P. Gagneux, M. Cheriyan, N. Hurtado-Ziola, E.C. van der Linden, D. Anderson, H. McClure, A. Varki, and N.M. Varki, Human-specific regulation of alpha 2-6-linked sialic acids, J Biol Chem 278 (2003), 48245-48250.

61. A. Garg, and J.P. Balthasar, Investigation of the influence of FcRn on the distribution of IgG to the brain, AAPS J 11 (2009), 553-557.

62. T. Gentile, I.M. Borel, J. Angelucci, S. Miranda, and R.A. Margni, Preferential synthesis of asymmetric antibodies in rats immunized with paternal particulate antigens. Effect on pregnancy, J Reprod Immunol 22 (1992), 173-183. 
63. T.E. Golde, Open questions for Alzheimer's disease immunotherapy, Alzheimers Res Ther 6 (2014), 3.

64. T. Guhr, J. Bloem, N.I. Derksen, M. Wuhrer, A.H. Koenderman, R.C. Aalberse, and T. Rispens, Enrichment of sialylated IgG by lectin fractionation does not enhance the efficacy of immunoglobulin $\mathrm{G}$ in a murine model of immune thrombocytopenia, PLoS One 6 (2011), e21246.

65. O. Hamid, C. Robert, A. Daud, F.S. Hodi, W.J. Hwu, R. Kefford, J.D. Wolchok, P. Hersey, R.W. Joseph, J.S. Weber, R. Dronca, T.C. Gangadhar, A. Patnaik, H. Zarour, A.M. Joshua, K. Gergich, J. Elassaiss-Schaap, A. Algazi, C. Mateus, P. Boasberg, P.C. Tumeh, B. Chmielowski, S.W.

Ebbinghaus, X.N. Li, S.P. Kang, and A. Ribas, Safety and tumor responses with lambrolizumab (anti-PD-1) in melanoma, N Engl J Med 369 (2013), 134-144.

66. N. Hamza, U. Hershberg, C.G.M. Kallenberg, A. Vissink, F.K.L. Spijkervet, H. Bootsma, F.G.M. Kroese, and N.A. Bos, Ig Gene Analysis Reveals Altered Selective Pressures on Ig-Producing Cells in Parotid Glands of Primary Sjogren's Syndrome Patients, Journal of Immunology 194 (2015), 514-521.

67. A.S. Haqqani, N. Caram-Salas, W. Ding, E. Brunette, C.E. Delaney, E. Baumann, E. Boileau, and D. Stanimirovic, Multiplexed evaluation of serum and CSF pharmacokinetics of brain-targeting single-domain antibodies using a NanoLC-SRM-ILIS method, Mol Pharm 10 (2013), 1542-1556.

68. J.M. Hayes, E.F. Cosgrave, W.B. Struwe, M. Wormald, G.P. Davey, R. Jefferis, and P.M. Rudd, Glycosylation and Fc receptors, Curr Top Microbiol Immunol 382 (2014), 165-199.

69. K. Hensley, Neuroinflammation in Alzheimer's disease: mechanisms, pathologic consequences, and potential for therapeutic manipulation, J Alzheimers Dis 21 (2010), 1-14.

70. F. Herve, N. Ghinea, and J.M. Scherrmann, CNS delivery via adsorptive transcytosis, AAPS J 10 (2008), 455-472.

71. E. Holm, K. Sletten, and G. Husby, STRUCTURAL STUDIES OF A CARBOHYDRATE-CONTAINING IMMUNOGLOBULIN-LAMBDA-LIGHT-CHAIN AMYLOID-FIBRIL PROTEIN (AL) OF VARIABLE SUBGROUP-III, Biochemical Journal 239 (1986), 545-551.

72. J.J. Iliff, M. Wang, Y. Liao, B.A. Plogg, W. Peng, G.A. Gundersen, H. Benveniste, G.E. Vates, R. Deane, S.A. Goldman, E.A. Nagelhus, and M. Nedergaard, A paravascular pathway facilitates CSF flow through the brain parenchyma and the clearance of interstitial solutes, including amyloid beta, Sci Transl Med 4 (2012), 147ra111.

73. G.A. Ingram, Lectins and lectin-like molecules in lower plants. I. Marine algae (review), Dev Comp Immunol 9 (1985), 1-10.

74. R. Jefferis, Antibody therapeutics: isotype and glycoform selection, Expert Opinion on Biological Therapy 7 (2007), 1401-1413.

75. Y.J. Jeong, H.J. Kang, K.H. Bae, M.G. Kim, and S.J. Chung, Efficient selection of IgG Fc domainbinding peptides fused to fluorescent protein using E. coli expression system and dot-blotting assay, Peptides 31 (2010), 202-206.

76. J.F. Jordao, C.A. Ayala-Grosso, K. Markham, Y. Huang, R. Chopra, J. McLaurin, K. Hynynen, and I. Aubert, Antibodies targeted to the brain with image-guided focused ultrasound reduces amyloid-beta plaque load in the TgCRND8 mouse model of Alzheimer's disease, PLoS One 5 (2010), e10549.

77. J.F. Jordao, E. Thevenot, K. Markham-Coultes, T. Scarcelli, Y.Q. Weng, K. Xhima, M. O'Reilly, Y. Huang, J. McLaurin, K. Hynynen, and I. Aubert, Amyloid-beta plaque reduction, endogenous antibody delivery and glial activation by brain-targeted, transcranial focused ultrasound, Exp Neurol 248 (2013), 16-29.

78. R.N. Kalaria, Cerebrovascular degeneration is related to amyloid-beta protein deposition in Alzheimer's disease, Ann N Y Acad Sci 826 (1997), 263-271. 
79. Y. Kaneko, F. Nimmerjahn, and J.V. Ravetch, Anti-inflammatory activity of immunoglobulin G resulting from Fc sialylation, Science 313 (2006), 670-673.

80. M. Karimi, K. Sletten, and P. Westermark, Biclonal systemic AL-amyloidosis with one glycosylated and one nonglycosylated AL-protein, Scandinavian Journal of Immunology 57 (2003), 319-323.

81. F. Kasermann, D.J. Boerema, M. Ruegsegger, A. Hofmann, S. Wymann, A.W. Zuercher, and S. Miescher, Analysis and functional consequences of increased Fab-sialylation of intravenous immunoglobulin (IVIG) after lectin fractionation, PLoS One 7 (2012), e37243.

82. S. Khurana, V. Raghunathan, and D.M. Salunke, The variable domain glycosylation in a monoclonal antibody specific to GnRH modulates antigen binding, Biochemical and Biophysical Research Communications 234 (1997), 465-469.

83. A.C. Klaver, M.P. Coffey, L.M. Smith, D.A. Bennett, J.M. Finke, L. Dang, and D.A. Loeffler, ELISA measurement of specific non-antigen-bound antibodies to Abeta1-42 monomer and soluble oligomers in sera from Alzheimer's disease, mild cognitively impaired, and noncognitively impaired subjects, J Neuroinflammation 8 (2011), 93.

84. R.E. Kontermann, and U. Brinkmann, Bispecific antibodies, Drug Discov Today 20 (2015), 838847.

85. H. Kwon, A.C. Crisostomo, H.M. Smalls, and J.M. Finke, Anti-abeta oligomer IgG and surface sialic acid in intravenous immunoglobulin: measurement and correlation with clinical outcomes in Alzheimer's disease treatment, PLoS One 10 (2015), e0120420.

86. GAP 18-Month Study Results, http://www.baxter.com/gap/baxter_gap_study_data_table.pdf.

87. H.J. Lee, B. Engelhardt, J. Lesley, U. Bickel, and W.M. Pardridge, Targeting rat anti-mouse transferrin receptor monoclonal antibodies through blood-brain barrier in mouse, $J$ Pharmacol Exp Ther 292 (2000), 1048-1052.

88. H. Leibiger, D. Wustner, R.D. Stigler, and U. Marx, Variable domain-linked oligosaccharides of a human monoclonal IgG: structure and influence on antigen binding, Biochemical Journal $\mathbf{3 3 8}$ (1999), 529-538.

89. G. Leinenga, and J. Gotz, Scanning ultrasound removes amyloid-beta and restores memory in an Alzheimer's disease mouse model, Sci Transl Med 7 (2015), 278 ra233.

90. C.A. Lemere, Immunotherapy for Alzheimer's disease: hoops and hurdles, Mol Neurodegener 8 (2013), 36.

91. D. Leontyev, Y. Katsman, X.-Z. Ma, S. Miescher, F. Kaesermann, and D.R. Branch, Sialylationindependent mechanism involved in the amelioration of murine immune thrombocytopenia using intravenous gammaglobulin, Transfusion 52 (2012), 1799-1805.

92. M.J. Linman, J.D. Taylor, H. Yu, X. Chen, and Q. Cheng, Surface plasmon resonance study of protein-carbohydrate interactions using biotinylated sialosides, Anal Chem 80 (2008), 40074013.

93. A.S. Lossinsky, A.W. Vorbrodt, and H.M. Wisniewski, Ultracytochemical studies of vesicular and canalicular transport structures in the injured mammalian blood-brain barrier, Acta Neuropathol 61 (1983), 239-245.

94. Q.L. Ma, G.P. Lim, M.E. Harris-White, F. Yang, S.S. Ambegaokar, O.J. Ubeda, C.G. Glabe, B. Teter, S.A. Frautschy, and G.M. Cole, Antibodies against beta-amyloid reduce Abeta oligomers, glycogen synthase kinase-3beta activation and tau phosphorylation in vivo and in vitro, $J$ Neurosci Res 83 (2006), 374-384.

95. C. Magdelaine-Beuzelin, Q. Kaas, V. Wehbi, M. Ohresser, R. Jefferis, M.-P. Lefranc, and H. Watier, Structure-function relationships of the variable domains of monoclonal antibodies approved for cancer treatment, Critical Reviews in Oncology Hematology 64 (2007), 210-225. 
96. A.H. Massoud, M. Yona, D. Xue, F. Chouiali, H. Alturaihi, A. Ablona, W. Mourad, C.A. Piccirillo, and B.D. Mazer, Dendritic cell immunoreceptor: A novel receptor for intravenous immunoglobulin mediates induction of regulatory T cells, Journal of Allergy and Clinical Immunology 133 (2014), 853-+.

97. C. Mavoungou, and K. Schindowski: Immunotherapy with Anti-Abeta Monoclonal Antibodies in Alzheimer's Disease: A Critical Review on the Molecules in the Pipelines with Regulatory Considerations. In Frontiers in Clinical Drug Research - Alzheimer's Disorders. Volume 1. Edited by Ur Raman A: Bentham Science Publishers; 2013: 3-85.

98. K.J. McCann, C.H. Ottensmeier, A. Callard, C.M. Radcliffe, D.J. Harvey, R.A. Dwek, P.M. Rudd, B.J. Sutton, P. Hobby, and F.K. Stevenson, Remarkable selective glycosylation of the immunoglobulin variable region in follicular lymphoma, Molecular Immunology 45 (2008), 1567-1572.

99. Y. Meng, I. Sohar, D.E. Sleat, J.R. Richardson, K.R. Reuhl, R.B. Jenkins, G. Sarkar, and P. Lobel, Effective intravenous therapy for neurodegenerative disease with a therapeutic enzyme and a peptide that mediates delivery to the brain, Mol Ther 22 (2014), 547-553.

100. C.R. Middaugh, and G.W. Litman, ATYPICAL GLYCOSYLATION OF AN IGG MONOCLONAL CRYOIMMUNOGLOBULIN, Journal of Biological Chemistry 262 (1987), 3671-3673.

101. P.P. Monnier, R.J. Vigouroux, and N.G. Tassew, In Vivo Applications of Single Chain Fv (Variable Domain) (scFv) Fragments, Antibodies 2013 (2013), 193-208.

102. J. Moreth, C. Mavoungou, and K. Schindowski, Passive anti-amyloid immunotherapy in Alzheimer's disease: What are the most promising targets?, Immun Ageing 10 (2013), 18.

103. M.F. Naso, S.H. Tam, B.J. Scallon, and T.S. Raju, Engineering host cell lines to reduce terminal sialylation of secreted antibodies, Mabs 2 (2010), 519-527.

104. V. Neves, F. Aires-da-Silva, S. Corte Real, and M.A.R.B. Castanho, Antibody approaches to treat brain diseases, Trends Biotechnology 34 (2016), 36-48.

105. J. Niewoehner, B. Bohrmann, L. Collin, E. Urich, H. Sade, P. Maier, P. Rueger, J.O. Stracke, W. Lau, A.C. Tissot, H. Loetscher, A. Ghosh, and P.O. Freskgard, Increased brain penetration and potency of a therapeutic antibody using a monovalent molecular shuttle, Neuron 81 (2014), 4960.

106. S. Ogata, C. Shimizu, A. Franco, R. Touma, J.T. Kanegaye, B.P. Choudhury, N.N. Naidu, Y. Kanda, L.T. Hoang, M.L. Hibberd, A.H. Tremoulet, A. Varki, and J.C. Burns, Treatment response in kawasaki disease is associated with sialylation levels of endogenous but not therapeutic intravenous immunoglobulin g, PLoS One 8 (2013), e81448.

107. S. Ohshima-Hosoyama, H.A. Simmons, N. Goecks, V. Joers, C.R. Swanson, V. Bondarenko, R. Velotta, K. Brunner, L.D. Wood, R.H. Hruban, and M.E. Emborg, A monoclonal antibody-GDNF fusion protein is not neuroprotective and is associated with proliferative pancreatic lesions in parkinsonian monkeys, PLoS One 7 (2012), e39036.

108. S. Othy, S. Topcu, C. Saha, P. Kothapalli, S. Lacroix-Desmazes, F. Kaesermann, S. Miescher, J. Bayry, and S.V. Kaveri, Sialylation may be dispensable for reciprocal modulation of helper T cells by intravenous immunoglobulin, European Journal of Immunology 44 (2014), 2059-2063.

109. C.Y. Ou, K.S. Hsieh, Y.H. Chiou, Y.H. Chang, and L.P. Ger, A comparative study of initial use of intravenous immunoglobulin and prednisolone treatments in childhood idiopathic thrombocytopenic purpur, Acta Paediatr Taiwan 47 (2006), 226-231.

110. W.M. Pardridge, Y.S. Kang, J.L. Buciak, and J. Yang, Human insulin receptor monoclonal antibody undergoes high affinity binding to human brain capillaries in vitro and rapid transcytosis through the blood-brain barrier in vivo in the primate, Pharm Res 12 (1995), 807-816.

111. D.A. Patel, A. Puig-Canto, D.K. Challa, H. Perez Montoyo, R.J. Ober, and E.S. Ward, Neonatal Fc receptor blockade by Fc engineering ameliorates arthritis in a murine model, $\mathrm{J} /$ mmunol 187 (2011), 1015-1022. 
112. I. Perdivara, L.J. Deterding, C. Cozma, K.B. Tomer, and M. Przybylski, Glycosylation profiles of epitope-specific anti-beta-amyloid antibodies revealed by liquid chromatography-mass spectrometry, Glycobiology 19 (2009), 958-970.

113. J.F. Poduslo, G.L. Curran, and C.T. Berg, Macromolecular permeability across the blood-nerve and blood-brain barriers, Proc Natl Acad Sci U S A 91 (1994), 5705-5709.

114. J.F. Poduslo, and G.L. Curran, Polyamine modification increases the permeability of proteins at the blood-nerve and blood-brain barriers, J Neurochem 66 (1996), 1599-1609.

115. J.F. Poduslo, M. Ramakrishnan, S.S. Holasek, M. Ramirez-Alvarado, K.K. Kandimalla, E.J. Gilles, G.L. Curran, and T.M. Wengenack, In vivo targeting of antibody fragments to the nervous system for Alzheimer's disease immunotherapy and molecular imaging of amyloid plaques, $J$ Neurochem 102 (2007), 420-433.

116. Z. Pourpak, A. Aghamohammadi, L. Sedighipour, A. Farhoudi, M. Movahedi, M. Gharagozlou, Z. Chavoshzadeh, L. Jadid, N. Rezaei, and M. Moin, Effect of regular intravenous immunoglobulin therapy on prevention of pneumonia in patients with common variable immunodeficiency, $J$ Microbiol Immunol Infect 39 (2006), 114-120.

117. D. Pyne, M. Ehrenstein, and V. Morris, The therapeutic uses of intravenous immunoglobulins in autoimmune rheumatic diseases, Rheumatology (Oxford) 41 (2002), 367-374.

118. C.M. Radcliffe, J.N. Arnold, D.M. Suter, M.R. Wormald, D.J. Harvey, L. Royle, Y. Mimura, Y. Kimura, R.B. Sim, S. Inoges, M. Rodriguez-Calvillo, N. Zabalegui, A. Lopez-Diaz de Cerio, K.N. Potter, C.I. Mockridge, R.A. Dwek, M. Bendandi, P.M. Rudd, and F.K. Stevenson, Human follicular lymphoma cells contain oligomannose glycans in the antigen-binding site of the B-cell receptor, Journal of Biological Chemistry 282 (2007), 7405-7415.

119. M. Ramakrishnan, K.K. Kandimalla, T.M. Wengenack, K.G. Howell, and J.F. Poduslo, Surface plasmon resonance binding kinetics of Alzheimer's disease amyloid beta peptide-capturing and plaque-binding monoclonal antibodies, Biochemistry 48 (2009), 10405-10415.

120. T.J. Raub, and K.L. Audus, Adsorptive endocytosis and membrane recycling by cultured primary bovine brain microvessel endothelial cell monolayers, J Cell Sci 97 ( Pt 1) (1990), 127-138.

121. N.R. Relkin, P. Szabo, B. Adamiak, T. Burgut, C. Monthe, R.W. Lent, S. Younkin, L. Younkin, R. Schiff, and M.E. Weksler, 18-Month study of intravenous immunoglobulin for treatment of mild Alzheimer disease, Neurobiol Aging 30 (2009), 1728-1736.

122. Y. Rombouts, A. Willemze, J.J.B.C. van Beers, J. Shi, P.F. Kerkman, L. van Toorn, G.M.C. Janssen, A. Zaldumbide, R.C. Hoeben, G.J.M. Pruijn, A.M. Deelder, G. Wolbink, T. Rispens, P.A. van Veelen, T.W.J. Huizinga, M. Wuhrer, L.A. Trouw, H.U. Scherer, and R.E.M. Toes, Extensive glycosylation of ACPA-IgG variable domains modulates binding to citrullinated antigens in rheumatoid arthritis, Annals of the Rheumatic Diseases 75 (2016), 578-585.

123. D.C. Roopenian, and S. Akilesh, FcRn: the neonatal Fc receptor comes of age, Nat Rev Immunol 7 (2007), 715-725.

124. M. Rotman, M.M. Welling, M.L. van den Boogaard, L.G. Moursel, L.M. van der Graaf, M.A. van Buchem, S.M. van der Maarel, and L. van der Weerd, Fusion of hlgG1-Fc to 111In-anti-amyloid single domain antibody fragment $\mathrm{VHH}-\mathrm{pa} 2 \mathrm{H}$ prolongs blood residential time in APP/PS1 mice but does not increase brain uptake, Nucl Med Biol 42 (2015), 695-702.

125. K.L. Sachen, M.J. Strohman, J. Singletary, A.A. Alizadeh, N.H. Kattah, C. Lossos, E.D. Mellins, S. Levy, and R. Levy, Self-antigen recognition by follicular lymphoma B-cell receptors, Blood 120 (2012), 4182-4190.

126. S. Salloway, R. Sperling, N.C. Fox, K. Blennow, W. Klunk, M. Raskind, M. Sabbagh, L.S. Honig, A.P. Porsteinsson, S. Ferris, M. Reichert, N. Ketter, B. Nejadnik, V. Guenzler, M. Miloslavsky, D. Wang, Y. Lu, J. Lull, I.C. Tudor, E. Liu, M. Grundman, E. Yuen, R. Black, H.R. Brashear, Bapineuzumab, 
and I. Clinical Trial, Two phase 3 trials of bapineuzumab in mild-to-moderate Alzheimer's disease, N Engl J Med 370 (2014), 322-333.

127. K.M. Sand, M. Bern, J. Nilsen, H.T. Noordzij, I. Sandlie, and J.T. Andersen, Unraveling the Interaction between FcRn and Albumin: Opportunities for Design of Albumin-Based Therapeutics, Front Immunol 5 (2014), 682.

128. G. Sarkar, G.L. Curran, E. Mahlum, T. Decklever, T.M. Wengenack, A. Blahnik, B. Hoesley, V.J. Lowe, J.F. Poduslo, and R.B. Jenkins, A carrier for non-covalent delivery of functional betagalactosidase and antibodies against amyloid plaques and IgM to the brain, PLoS One 6 (2011), e28881.

129. D. Schenk, R. Barbour, W. Dunn, G. Gordon, H. Grajeda, T. Guido, K. Hu, J. Huang, K. JohnsonWood, K. Khan, D. Kholodenko, M. Lee, Z. Liao, I. Lieberburg, R. Motter, L. Mutter, F. Soriano, G. Shopp, N. Vasquez, C. Vandevert, S. Walker, M. Wogulis, T. Yednock, D. Games, and P. Seubert, Immunization with amyloid-beta attenuates Alzheimer-disease-like pathology in the PDAPP mouse, Nature 400 (1999), 173-177.

130. F. Schlachetzki, C. Zhu, and W.M. Pardridge, Expression of the neonatal Fc receptor (FcRn) at the blood-brain barrier, J Neurochem 81 (2002), 203-206.

131. D. Schneider, M. Duehren-von Minden, A. Alkhatib, C. Setz, C.A.M. van Bergen, M. BenkisserPetersen, I. Wilhelm, S. Villringer, S. Krysov, G. Packham, K. Zirlik, W. Roemer, C. Buske, F.K. Stevenson, H. Veelken, and H. Jumaa, Lectins from opportunistic bacteria interact with acquired variable-region glycans of surface immunoglobulin in follicular lymphoma, Blood 125 (2015), 3287-3296.

132. I. Schwab, and F. Nimmerjahn, Role of sialylation in the anti-inflammatory activity of intravenous immunoglobulin - F(ab ')(2) versus Fc sialylation, Clinical and Experimental Immunology 178 (2014), 97-99.

133. J.-F. Seite, D. Cornec, Y. Renaudineau, P. Youinou, R.A. Mageed, and S. Hillion, IVIg modulates BCR signaling through CD22 and promotes apoptosis in mature human B lymphocytes, Blood 116 (2010), 1698-1704.

134. J. Sevigny, P. Chiao, T. Bussiere, P.H. Weinreb, L. Williams, M. Maier, R. Dunstan, S. Salloway, T. Chen, Y. Ling, J. O'Gorman, F. Qian, M. Arastu, M. Li, S. Chollate, M.S. Brennan, O. QuinteroMonzon, R.H. Scannevin, H.M. Arnold, T. Engber, K. Rhodes, J. Ferrero, Y. Hang, A. Mikulskis, J. Grimm, C. Hock, R.M. Nitsch, and A. Sandrock, The antibody aducanumab reduces Abeta plaques in Alzheimer's disease, Nature 537 (2016), 50-56.

135. G.D. Silverberg, G. Heit, S. Huhn, R.A. Jaffe, S.D. Chang, H. Bronte-Stewart, E. Rubenstein, K. Possin, and T.A. Saul, The cerebrospinal fluid production rate is reduced in dementia of the Alzheimer's type, Neurology 57 (2001), 1763-1766.

136. P. Sondermann, A. Pincetic, J. Maamary, K. Lammens, and J.V. Ravetch, General mechanism for modulating immunoglobulin effector function, Proc Natl Acad Sci U S A 110 (2013), 9868-9872.

137. P.S. Sorensen, Treatment of multiple sclerosis with intravenous immunoglobulin: review of clinical trials, Neurol Sci 24 Suppl 4 (2003), S227-230.

138. J. Stadlmann, M. Pabst, D. Kolarich, R. Kunert, and F. Altmann, Analysis of immunoglobulin glycosylation by LC-ESI-MS of glycopeptides and oligosaccharides, Proteomics 8 (2008), 28582871.

139. J. Stadlmann, A. Weber, M. Pabst, H. Anderle, R. Kunert, H.J. Ehrlich, H. Peter Schwarz, and F. Altmann, A close look at human IgG sialylation and subclass distribution after lectin fractionation, Proteomics 9 (2009), 4143-4153.

140. T.L. Sudduth, A. Greenstein, and D.M. Wilcock, Intracranial injection of Gammagard, a human IVIg, modulates the inflammatory response of the brain and lowers Abeta in APP/PS1 mice along a different time course than anti-Abeta antibodies, J Neurosci 33 (2013), 9684-9692. 
141. R.K. Sumbria, E.K. Hui, J.Z. Lu, R.J. Boado, and W.M. Pardridge, Disaggregation of amyloid plaque in brain of Alzheimer's disease transgenic mice with daily subcutaneous administration of a tetravalent bispecific antibody that targets the transferrin receptor and the Abeta amyloid peptide, Mol Pharm 10 (2013), 3507-3513.

142. H. Tachibana, J.Y. Kim, and S. Shirahata, Building high affinity human antibodies by altering the glycosylation on the light chain variable region in $\mathrm{N}$-acetylglucosamine-supplemented hybridoma cultures, Cytotechnology 23 (1997), 151-159.

143. Y. Tamura, K. Hamajima, K. Matsui, S. Yanoma, M. Narita, N. Tajima, K.Q. Xin, D. Klinman, and K. Okuda, The $\mathrm{F}(\mathrm{ab})$ '2 fragment of an Abeta-specific monoclonal antibody reduces Abeta deposits in the brain, Neurobiol Dis 20 (2005), 541-549.

144. D.R. Thakker, M.R. Weatherspoon, J. Harrison, T.E. Keene, D.S. Lane, W.F. Kaemmerer, G.R. Stewart, and L.L. Shafer, Intracerebroventricular amyloid-beta antibodies reduce cerebral amyloid angiopathy and associated micro-hemorrhages in aged Tg2576 mice, Proc Natl Acad Sci U S A 106 (2009), 4501-4506.

145. E. Toubi, and A. Etzioni, Intravenous immunoglobulin in immunodeficiency states: state of the art, Clin Rev Allergy Immunol 29 (2005), 167-172.

146. P.M. Vaitla, and E.M. McDermott, The role of high-dose intravenous immunoglobulin in rheumatology, Rheumatology (Oxford) 49 (2010), 1040-1048.

147. F.S. van de Bovenkamp, T.R. Hafkenscheid, and Y. Rombouts, The emerging importance of IgG Fab glycosylation in immunity, J Immun 196 (2016), 1435-1441.

148. J.C. Villegas, and R.D. Broadwell, Transcytosis of protein through the mammalian cerebral epithelium and endothelium. II. Adsorptive transcytosis of WGA-HRP and the blood-brain and brain-blood barriers, J Neurocytol 22 (1993), 67-80.

149. S.C. Wallick, E.A. Kabat, and S.L. Morrison, GLYCOSYLATION OF A VH RESIDUE OF A MONOCLONAL-ANTIBODY AGAINST ALPHA(1-6) DEXTRAN INCREASES ITS AFFINITY FOR ANTIGEN, Journal of Experimental Medicine 168 (1988), 1099-1109.

150. N. Washburn, I. Schwab, D. Ortiz, N. Bhatnagar, J.C. Lansing, A. Medeiros, S. Tyler, D. Mekala, E. Cochran, H. Sarvaiya, K. Garofalo, R. Meccariello, J.W. Meador, III, L. Rutitzky, B.C. Schultes, L. Ling, W. Avery, F. Nimmerjahn, A.M. Manning, G.V. Kaundinya, and C.J. Bosques, Controlled tetra-Fc sialylation of IVIg results in a drug candidate with consistent enhanced antiinflammatory activity, Proceedings of the National Academy of Sciences of the United States of America 112 (2015), E1297-E1306.

151. M.E. Weksler, and M. Goodhardt, Do age-associated changes in 'physiologic' autoantibodies contribute to infection, atherosclerosis, and Alzheimer's disease?, Exp Gerontol 37 (2002), 971 979.

152. A.E. Wiedeman, D.M. Santer, W. Yan, S. Miescher, F. Kaesermann, and K.B. Elkon, Contrasting Mechanisms of Interferon-alpha Inhibition by Intravenous Immunoglobulin After Induction by Immune Complexes Versus Toll-like Receptor Agonists, Arthritis and Rheumatism 65 (2013), 2713-2723.

153. D.M. Wilcock, J. Alamed, P.E. Gottschall, J. Grimm, A. Rosenthal, J. Pons, V. Ronan, K. Symmonds, M.N. Gordon, and D. Morgan, Deglycosylated anti-amyloid-beta antibodies eliminate cognitive deficits and reduce parenchymal amyloid with minimal vascular consequences in aged amyloid precursor protein transgenic mice, J Neurosci 26 (2006), 53405346.

154. A. Wright, M.H. Tao, E.A. Kabat, and S.L. Morrison, ANTIBODY VARIABLE REGION GLYCOSYLATION - POSITION EFFECTS ON ANTIGEN-BINDING AND CARBOHYDRATE STRUCTURE, Embo Journal 10 (1991), 2717-2723. 
155. P.-C. Xu, S.-J. Gou, X.-W. Yang, Z. Cui, X.-Y. Jia, M. Chen, and M.-H. Zhao, Influence of variable domain glycosylation on anti-neutrophil cytoplasmic autoantibodies and anti-glomerular basement membrane autoantibodies, Bmc Immunology 13 (2012), .

156. K. Yamada, C. Yabuki, P. Seubert, D. Schenk, Y. Hori, S. Ohtsuki, T. Terasaki, T. Hashimoto, and T. Iwatsubo, Abeta immunotherapy: intracerebral sequestration of Abeta by an anti-Abeta monoclonal antibody 266 with high affinity to soluble Abeta, J Neurosci 29 (2009), 11393-11398.

157. X. Yi, and A.V. Kabanov, Brain delivery of proteins via their fatty acid and block copolymer modifications, J Drug Target 21 (2013), 940-955.

158. A. Youings, S.C. Chang, R.A. Dwek, and I.G. Scragg, Site-specific glycosylation of human immunoglobulin $\mathrm{G}$ is altered in four rheumatoid arthritis patients, Biochemical Journal 314 (1996), 621-630.

159. X. Yu, S. Vasiljevic, D.A. Mitchell, M. Crispin, and C.N. Scanlan, Dissecting the molecular mechanism of IVIg therapy: the interaction between serum IgG and DC-SIGN is independent of antibody glycoform or Fc domain, J Mol Biol 425 (2013), 1253-1258.

160. Y.J. Yu, Y. Zhang, M. Kenrick, K. Hoyte, W. Luk, Y. Lu, J. Atwal, J.M. Elliott, S. Prabhu, R.J. Watts, and M.S. Dennis, Boosting brain uptake of a therapeutic antibody by reducing its affinity for a transcytosis target, Sci Transl Med 3 (2011), 84ra44.

161. A.C. Zenclussen, T. Gentile, G. Kortebani, A. Mazzolli, and R. Margni, Asymmetric antibodies and pregnancy, American Journal of Reproductive Immunology 45 (2001), 289-294.

162. Y. Zhang, and W.M. Pardridge, Mediated efflux of IgG molecules from brain to blood across the blood-brain barrier, J Neuroimmunol 114 (2001), 168-172.

163. D.L. Zhu, H. McCarthy, C.H. Ottensmeier, P. Johnson, T.J. Hamblin, and F.K. Stevenson, Acquisition of potential $\mathrm{N}$-glycosylation sites in the immunoglobulin variable region by somatic mutation is a distinctive feature of follicular lymphoma, Blood 99 (2002), 2562-2568.

164. B.D. Zipser, C.E. Johanson, L. Gonzalez, T.M. Berzin, R. Tavares, C.M. Hulette, M.P. Vitek, V. Hovanesian, and E.G. Stopa, Microvascular injury and blood-brain barrier leakage in Alzheimer's disease, Neurobiol Aging 28 (2007), 977-986. 